\title{
Antioxidant and antimicrobial activities of phenolic acids rich extracts released from oat bran with the aid of carbohydrases
}

By Roaaya Alrahmany

A thesis submitted to the Faculty of Graduate and Postdoctoral Affairs in partial fulfillment of the requirements for the degree of

Master of Science

In

Food Science and Nutrition

Carleton University

Ottawa, Ontario

(C) 2012

Roaaya Alrahmany 
Library and Archives

Canada

Published Heritage

Branch

395 Wellington Street

Ottawa ON K1A ON4

Canada
Bibliothèque et

Archives Canada

Direction du

Patrimoine de l'édition

395 , rue Wellington

Ottawa ON K1A ON4

Canada
Your file Votre référence

ISBN: 978-0-494-94292-5

Our file Notre référence

ISBN: $978-0-494-94292-5$
NOTICE:

The author has granted a nonexclusive license allowing Library and Archives Canada to reproduce, publish, archive, preserve, conserve, communicate to the public by telecommunication or on the Internet, loan, distrbute and sell theses worldwide, for commercial or noncommercial purposes, in microform, paper, electronic and/or any other formats.

The author retains copyright ownership and moral rights in this thesis. Neither the thesis nor substantial extracts from it may be printed or otherwise reproduced without the author's permission.
AVIS:

L'auteur a accordé une licence non exclusive permettant à la Bibliothèque et Archives Canada de reproduire, publier, archiver, sauvegarder, conserver, transmettre au public par télécommunication ou par l'Internet, prêter, distribuer et vendre des thèses partout dans le monde, à des fins commerciales ou autres, sur support microforme, papier, électronique et/ou autres formats.

L'auteur conserve la propriété du droit d'auteur et des droits moraux qui protege cette thèse. $\mathrm{Ni}$ la thèse ni des extraits substantiels de celle-ci ne doivent être imprimés ou autrement reproduits sans son autorisation.
In compliance with the Canadian Privacy Act some supporting forms may have been removed from this thesis.

While these forms may be included in the document page count, their removal does not represent any loss of content from the thesis.
Conformément à la loi canadienne sur la protection de la vie privée, quelques formulaires secondaires ont été enlevés de cette thèse.

Bien que ces formulaires aient inclus dans la pagination, il n'y aura aucun contenu manquant. 
بسم الله الرحن الرحيم

In The Name of Allah, The All-Merciful, The Ever-Merciful 


\section{Table of content}

List of Abbreviations.......................................................................................... 1

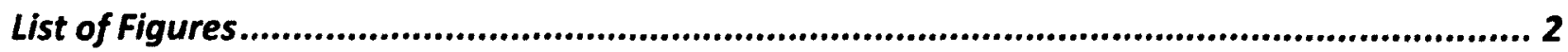

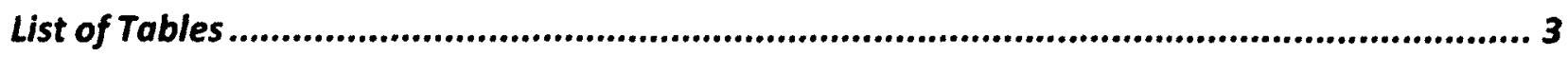

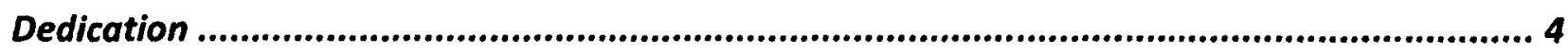

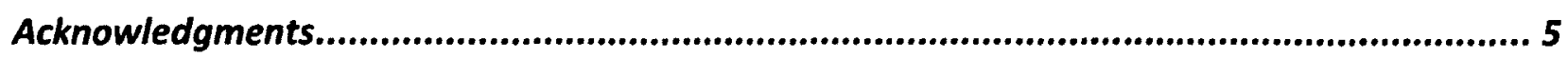

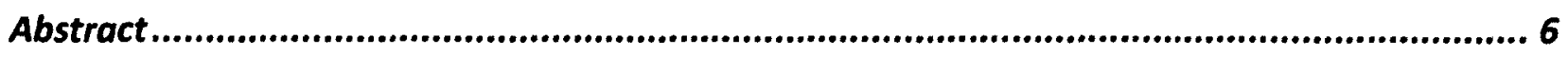

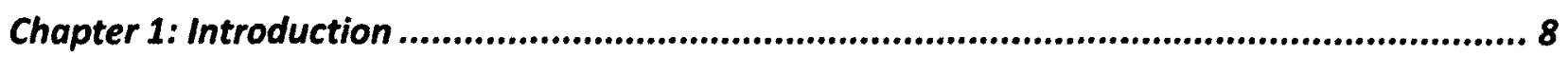

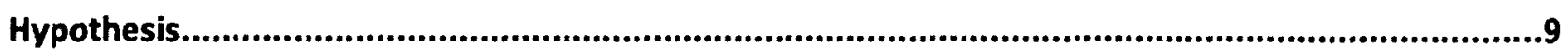

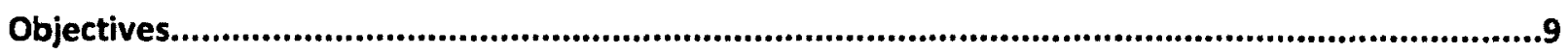

Chapter 2: Literature Review ..............................................................................10

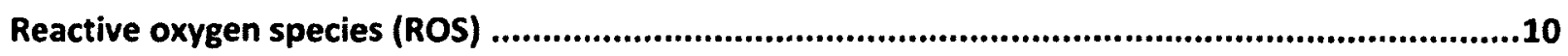

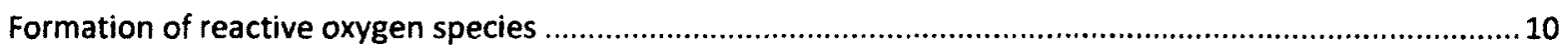

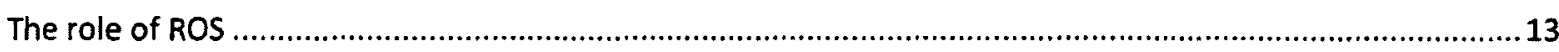

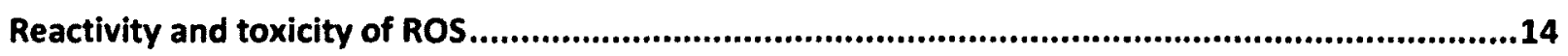

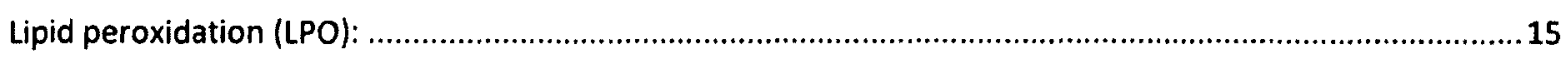

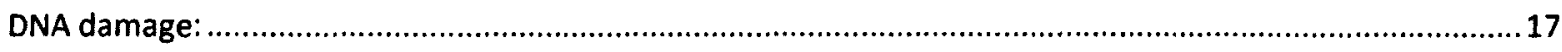

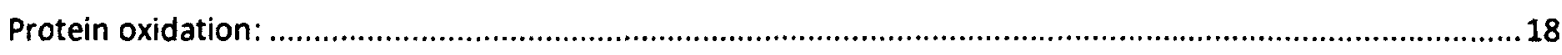

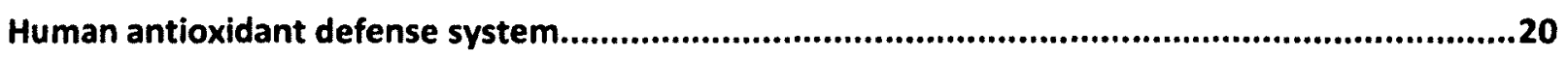

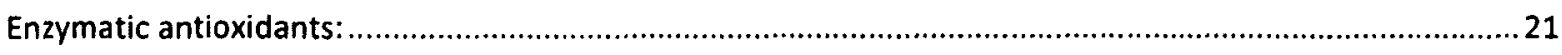

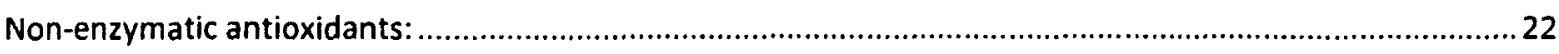




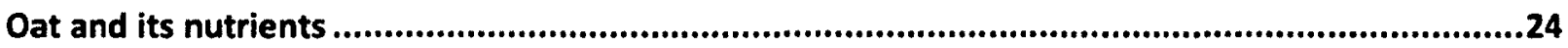

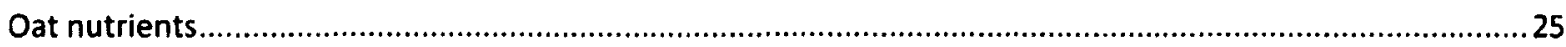

Extraction methods for polyphenols in cereals.....................................................................30

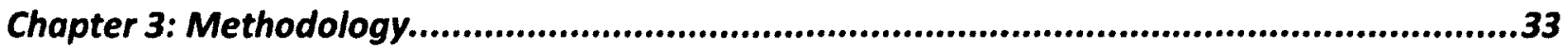

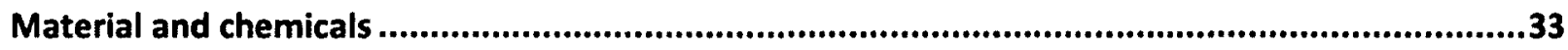

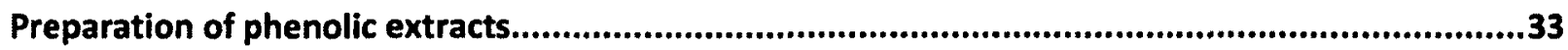

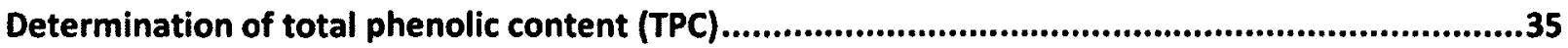

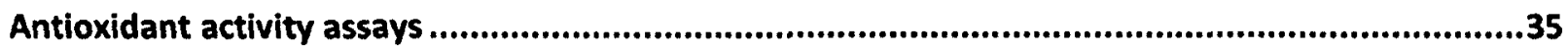

Determination of oxygen radical absorbance capacity (ORAC) ...............................................................35

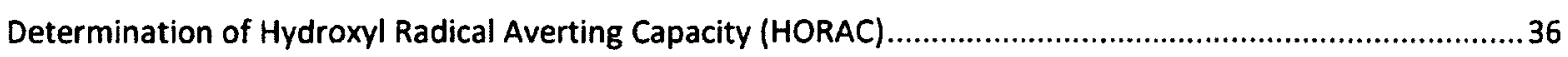

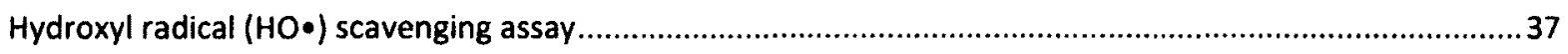

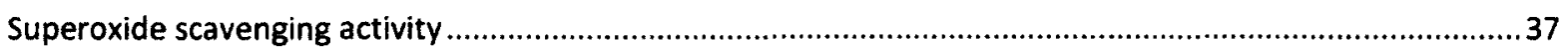

Determination of free radical scavenging activity by DPPH assay................................................................38

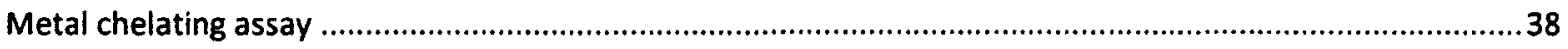

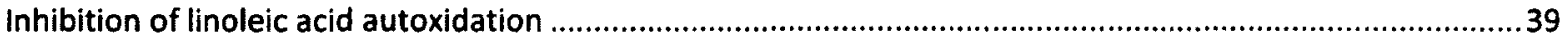

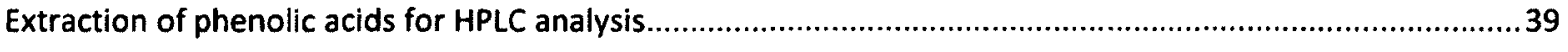

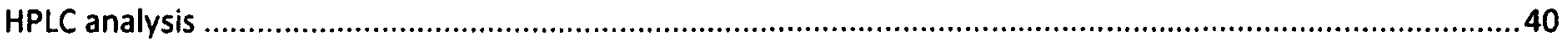

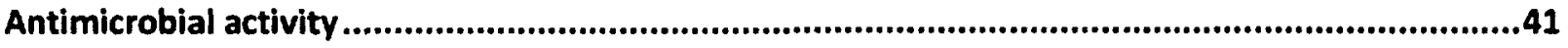

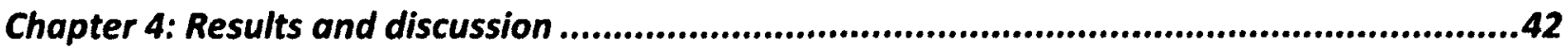

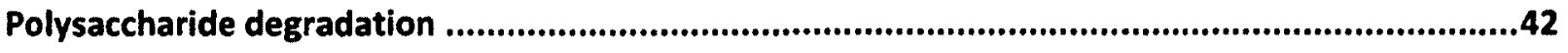

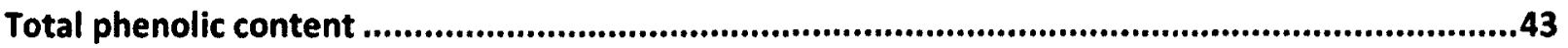


Hydroxyl Radical Antioxidant Capacity (HORAC) and Hydroxyl radical scavenging activity.

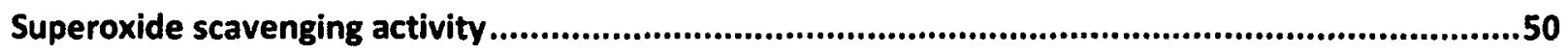

Diphenyl-1-picrylhydrazyl (DPPH) radical scavenging activity ..............................................5 51

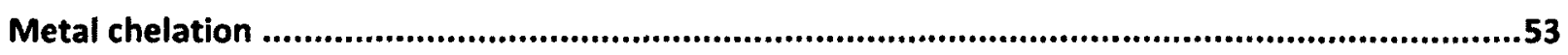

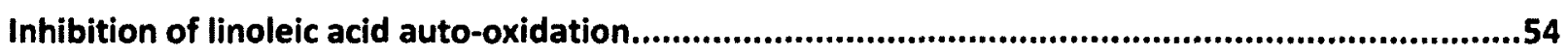

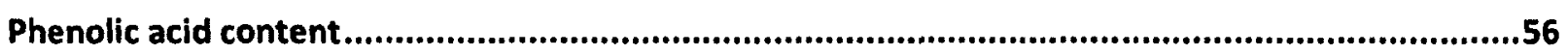

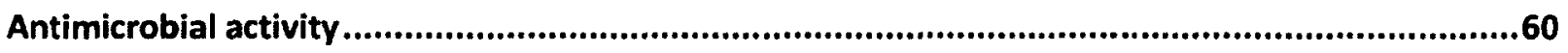

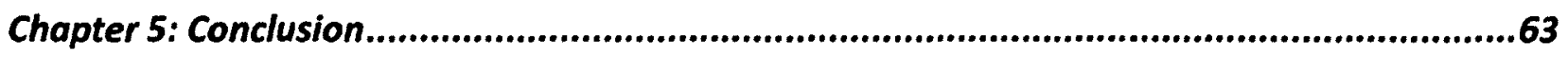

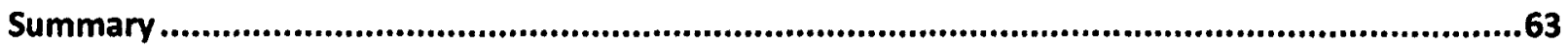

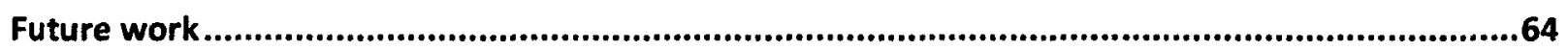

References .......................................................................................................65 


\section{List of Abbreviations}

(ROS) Reactive oxygen species

(SOD) Superoxide dismutase

(GSH) Glutathione

(PUFA) Polyunsaturated fatty acid

(NADPH oxidases) Nicotinamide adenine dinucleotide phosphate oxidases

(ATP) Adenosine-5-triphosphate

(LPO) Lipid peroxidation

(MDA) Malondialdehyde

(CAT) Catalase

(GPX) Glutathione peroxidise

(AV) Avenanthramide

(ORAC) Oxygen Radical Absorbance Capacity

(HORAC) Hydroxyl Radical Averting Capacity

(DPPH) 2,2-diphenyl-1-picrylhydrazyl

(HPLC) High Performance Liquid Chromatography

(8-OHdG) 8-hydroxydeoxyguanosine

(GAE) Gallic acid equivalent 


\section{List of Figures}

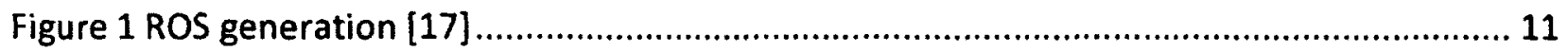

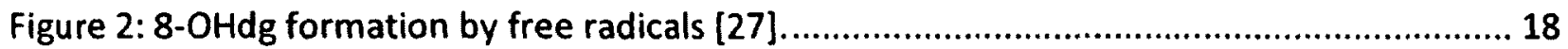

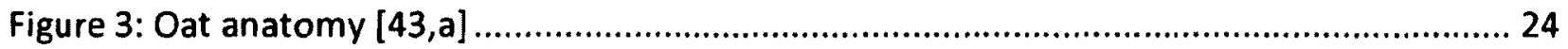

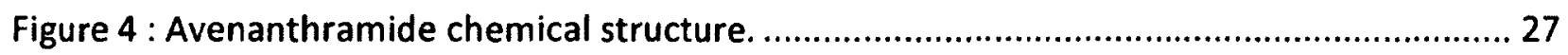

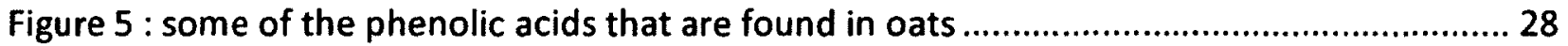

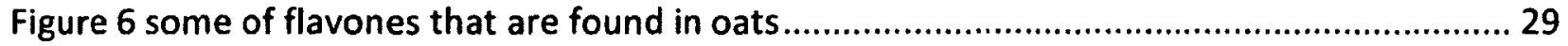

Figure 7: most common lignan chemical structure ...................................................... 29

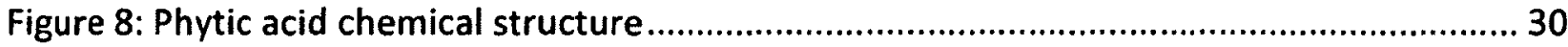

Figure 90: Effects of control and carbohydrases treated samples on the growth of

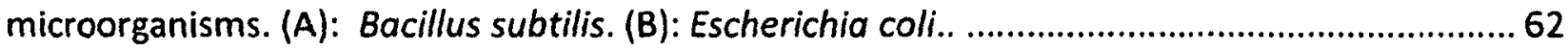




\section{List of Tables}

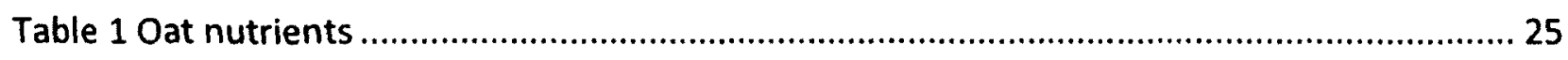

Table 2 Extraction condition of medium oat bran samples................................................ 34

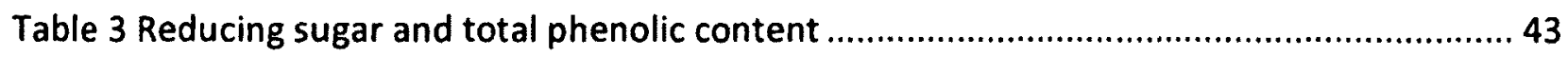

Table 4 Phenolic acids in control and different enzyme-treated oat bran samples .................. 59 


\section{Dedication}

This thesis is lovingly dedicated to

The people who were supporting and waiting for this achievement, but left before.

The people who support me back home especially mom and brother.

My family, Emad, Raghad, Yousof, Abbas and Abdumalik who have been my constant source of inspiration and supported me each step of the way to achieve what I dreamed of.

My best friends who always beside me, Dina Almohsen. 


\section{Acknowledgments}

Alhamdoallah, Thankful to god for everything I have been through so far. With Allah everything is possible.

Thanks to the King Abdullah for the opportunity to continue my studying and achieve my dreams through the King Abdullah foreign scholarship and the grant that support my study.

A special thanks to Dr. Apollinaire Tsopmo for his confidence in me and his support for this project.

I would like to thank friend and colleague Sara Jodayree for her help all the time and I wish to thank my committee members who were more than generous with their expertise and precious time.

Finally, I would like to thank the Department of Chemistry for giving me the opportunity to complete my research and study. 


\section{Abstract}

Many studies have demonstrated that the health promoting capabilities of oats are due to the presence of antioxidants compounds, such as phenolic acids and avenanthramide (only present in oats), and also to dietary fibers (e.g. $\beta$-glucan), and high content of lysine, a limiting amino acid in other cereals. Extraction of phenolic compounds in oat is difficult because up to $80 \%$ are conjugated with cell wall polysaccharides lipids. The aim of the research was to investigate the effect of four polysaccharide degrading enzymes on the release of polyphenols and biological properties of resulting polyphenol rich extracts.

Aqueous solutions of medium oat bran flour were therefore treated with viscozyme, cellulase, alpha-amylase, and amyloglucosidase, and extracted with equal volume of methanol. Total phenolic content, antioxidant and antimicrobial activities of the extracts were determined. The effects on these enzymes on the release of individual phenolic acids were quantified using reverse-phase HPLC chromatography.

The measurement of indices of antioxidant activities showed that treatment oat bran with the enzymes significantly increased radical scavenging and metal chelating capacities of samples. In the antimicrobial activity, viscozyme and cellulase treated samples had a significant inhibitory effect on the growth of the gram negative bacteria, E.coli.

The HPLC analysis showed the amount of free phenolic acids; such as ferulic acid and caffeic acid increased in samples treated with enzymes. The highest amount of caffeic acid was found in the alpha-amylase treated sample.

The pre-treatment of medium oat bran with the carbohydrases showed that more soluble phenolic acids were released and this was associated with increased antioxidant properties as 
well as inhibition of the growth of $E$. coli, a pathogen commonly encountered in foods. These data demonstrated that polysaccharide degrading enzymes could be used to obtain polyphenols rich fractions from bran (cereal by-products). This may find application in the formulation of nutraceuticals and functional food rich in antioxidants for health maintenance and reduction of risks of chronic diseases. 


\section{Chapter 1: Introduction}

Oat (Avena sativa) is one of the important cereal crops in Canada, and over the years interest in oats has increased [1]. Oat similar to the other grains belongs to Poaceae family [2]. Oats consumption is low compared to other cereals, but because they are often consumed as a whole grain, they have the advantage of providing the human's body with many phytochemicals [3]. Oat has been known to be used as a medicine or feed crop. Recently oats has been used in many products such as breakfast cereals, infant foods and beverages [4].

Oat is generally believed to be one of the best cereals from a health perspective since it contains many bioactive components, such as fiber (e.g. $\beta$-glucan), compounds with high antioxidant activity (e.g. tocopherol, phenolic compounds), essential fatty acids (e.g. $\alpha$-linoleic acid), and phytosterols [5]. Most of these phytochemical components are concentrated in the oat bran, which is the outer layer of the kernel [6]. Phytochemicals have the ability to prevent chronic diseases, such as cardiovascular diseases, and some cancers [4]. The biological effects of the phytochemical components of oat are due to their antioxidant and cholesterol lowering properties $[2,7]$.

Phenolic compounds are a group of phytochemicals known to possess antioxidant properties. Many of them such as avenanthramides, flavonoids, and phenolic acids are present in oat bran. Avenanthramides are unique group of phenolic compounds found only in oats. It is well known that phenolic compounds can scavenge free radicals and chelate metal ions, thereby preventing potential damage that oxidant molecules can cause to important cellular 
components, such as DNA, lipids, and proteins. In food, antioxidants contribute to the stability and enhance sensory attributes [3].

Extracting phenolic compounds in cereals are challenging, because $80 \%$ of phenolic compounds in cereals are bound to polysaccharides and proteins [8]. As a consequence, to release phenolic acids, basic or acid hydrolysis are commonly used. A few studies have been conducted on the use carbohydrases hydrolytic to increase extraction of phenolics in cereals, such as wheat; however, the technique hasn't been applied to oats.

\section{Hypothesis}

The use of viscozyme, alpha-amylase, cellulase and amyloglucosidase will increase extraction efficiency of oat phenolic acids as well as antioxidant and antimicrobial properties of resulting extracts.

\section{Objectives}

1. Treat oat bran with carbohydrases at optimum $\mathrm{pH}$ and temperature to attain a desired viscosity and enhance phenolic compound extraction.

2. Measure the amount of reducing sugar and total phenolic content of extracts.

3. Determine antioxidant activities of phenolic extracts.

4. Quantify individual phenolic acids contents by high performance liquid chromatography (HPLC) in the extracted materials.

5. Determine the antimicrobial activity of extracts. 


\section{Chapter 2: Literature Review}

\section{Reactive oxygen species (ROS)}

Oxygen is an essential element for the survival of humans, yet it also can damage or cause cell death [9]. Molecular oxygen is present in the atmosphere as a stable triplet biradical $\left({ }^{3} \mathrm{O}_{2}\right)$. When this oxygen is inhaled, it goes through a reduction process in the mitochondria to form water. During this process, molecular oxygen is incompletely reduced to a reactive intermediate known as superoxide radical anion $\left(\mathrm{O}_{2} \bullet-\right)$ which can be further converted to, hydroxyl radicals $(\mathrm{HO} \bullet)$ and peroxyl radicals (ROO•). Non-radical derivatives are also formed; a few examples of non-radical derivatives are hydrogen peroxide $\left(\mathrm{H}_{2} \mathrm{O}_{2}\right)$, and single oxygen $\left({ }^{1} \mathrm{O}_{2}\right)$. These reactive intermediate are called reactive oxygen species (ROS) $[10,11]$. ROS react with complex cellular biomolecules and it can cause damage [12].

Free radicals are any chemicals that contain atoms with an unpaired electron in its outer orbit. The unpaired electron in free radical can be located in any atom. In contrast, free radicals that are part of ROS only have the unpaired electron on the oxygen atom. ROS and other free radicals have the same characteristics, i.e., a short life, instability, and the ability to react with other molecules to achieve stability, which can lead to cellular damages [13].

\section{Formation of reactive oxygen species}

During the previously-mentioned metabolism process in which oxygen is metabolized to form water, many free radicals are formed as intermediates products. The first and the main production of ROS is the addition of one electron to the stable $\mathrm{O}_{2}$ (reduction), leaving the oxygen with unpaired electron, creating superoxide anion $\mathrm{O}_{2}{ }^{\circ-}$ [Figure 1]. The main 
endogenous source is the electron transport chain in the mitochondria for adenosine-5'triphosphate (ATP) generation. This anion interacts with other molecules to produce other ROS, such as hydroxyl radical $\bullet O H$. The reduction of $\mathrm{O}_{2} \bullet^{--}$that results in the formation of hydrogen peroxide $\mathrm{H}_{2} \mathrm{O}_{2}$ by the addition of an electron followed by protonation. In the presence of metal, such as $\mathrm{Fe}$ or $\mathrm{Cu}, \mathrm{H}_{2} \mathrm{O}_{2}$ generates the most active $\mathrm{ROS} \bullet \mathrm{OH}$ through the Fenton reaction. However, the singlet oxygen is formed in the presence of photosensitized molecules such as riboflavin $[9,14]$. In addition to that, the donation of an electron from $\bullet \mathrm{O}_{2}$ to iron $\left(\mathrm{Fe}^{3+}\right)$ to reduce to $\left(\mathrm{Fe}^{2+}\right)$ (by Harber-Weiss reaction) followed by a reduction to $\mathrm{H}_{2} \mathrm{O}_{2}$ and resulting in the generation of hydroxyl radical $(\bullet \mathrm{OH})$ (by the Fenton's reaction) $[13,15,16]$.

$$
\begin{gathered}
\cdot \mathrm{O}_{2}+\mathrm{Fe}^{3+} \rightarrow \mathrm{O}_{2}+\mathrm{Fe}^{2+} \\
2 \cdot \mathrm{O}^{2}+2 \mathrm{H}^{+} \stackrel{\text { SOD }}{\longrightarrow} \mathrm{O}_{2}+\mathrm{H}_{2} \mathrm{O}_{2} \mathrm{Fe}^{3+}
\end{gathered}
$$

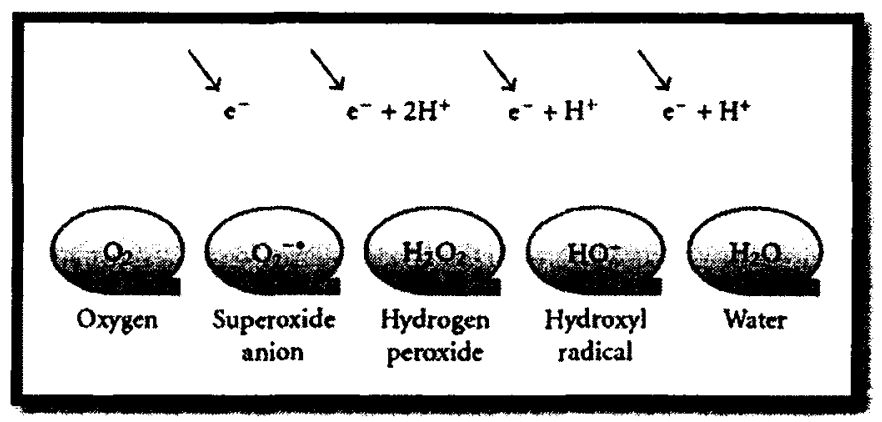

Figure 1 ROS generation [17]

Superoxide $\bullet \mathrm{O}_{2}$ : In biological systems, the superoxide anion is fairly toxic and has a half-life of $2-4 \mu \mathrm{s} ;$ nevertheless, it is important in allowing phagocytes to kill and engulf bacteria strains. $\mathrm{O}_{2} \bullet^{-}$has oxidizing and reducing capabilities. $\mathrm{O}_{2} \bullet^{-}$is oxidised by an enzyme called superoxide dismutase (SOD), to form $\mathrm{H} 2 \mathrm{O} 2[18,19]$. 
Hydrogen peroxide $\mathrm{H}_{2} \mathrm{O}_{2}: \mathrm{H}_{2} \mathrm{O}_{2}$ is moderately reactive and has a relatively long half life (1ms). These ROS are not free radicals because they do not have unpaired electron, but they are the main source for $\cdot \mathrm{OH}$ in the presence of transition metals, and they have the same damaging effects on the cell as $\mathrm{O}_{2} \bullet^{--}$. Also, they create some specific damages, such as damage to DNA, inactivating some enzymes by oxidizing their thiol groups, and membrane disruption. Glutathione peroxidise catalyze the glutathione (GSH) to glutathione disulfide (GSSG) in the presence of $\mathrm{H}_{2} \mathrm{O}_{2}$.

$$
2 \mathrm{GSH}+\mathrm{H}_{2} \mathrm{O}_{2} \stackrel{G P x}{\longrightarrow} \mathrm{GSSG}+2 \mathrm{H}_{2} \mathrm{O}
$$

However, some of these damages could be reduced depending on the reaction of $\mathrm{H}_{2} \mathrm{O}_{2}$ and $\mathrm{O}_{2} \bullet^{-}$to create $\bullet \mathrm{OH}$ in the presence of iron. As previously mentioned, in the $\mathrm{O}_{2} \bullet^{-}$there is a disposal for each of these species of free radical. Catalase is the enzyme that is responsible for converting $\mathrm{H}_{2} \mathrm{O}_{2}$ to $\mathrm{H}_{2} \mathrm{O}$.

It has been shown that $\mathrm{H}_{2} \mathrm{O}_{2}$ is important because it acts as a secondary messenger for signaling the immune system to initiate the healing process, and some peroxidises use $\mathrm{H}_{2} \mathrm{O}_{2}$ in the oxidizing reaction involving the synthesis of complex organic molecules $[13,15,16,18]$.

Hydroxyl radical $\bullet \mathrm{OH}$ : among all the $\mathrm{ROS}$ or free radicals $\bullet \mathrm{OH}$ is the most reactive. One mechanism by which this radical is formed is the exposure of tissue to radiation; the radical is absorbed by water after which it is split between the covalent bonds of one of the oxygen hydrogen bonds or in the presence of metal ions, as was mentioned previously.

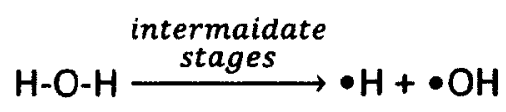


The hydroxyl radical can damage many molecules because it is not eliminated by any enzymatic activity. However, it can be removed by endogenous antioxidants, such as melatonin and dietary antioxidant, such as vitamin $\mathrm{E}$. Then the reaction that removes $\bullet \mathrm{OH}$ when it reacts with nearest carbon chain from a polyunsaturated fatty acid leaving carbon-centered radical (C•-). Under physiological conditions, this lead to the reaction of - $\mathrm{C} \cdot-$ and oxygen to form peroxyl radicals. The latter is so reactive that can react with fatty acids $[13,15,16,18]$.

$$
\begin{gathered}
-\mathrm{CH}+\bullet \mathrm{OH} \rightarrow-\mathrm{C} \bullet+\mathrm{H}_{2} \mathrm{O} \\
-\mathrm{C} \bullet-+\mathrm{O}_{2} \rightarrow-\mathrm{COO} \cdot \\
-\mathrm{COO} \cdot+-\mathrm{CH} \rightarrow-\mathrm{COOH}+-\mathrm{C} \bullet
\end{gathered}
$$

Singlet oxygen species ' $\mathrm{O}_{2}$ : This species is not a radical, but it has powerful damaging effects. The ${ }^{\prime} \mathrm{O}_{2}$ species is formed during the transfer of energy to oxygen or during the photosynthesis of pigments, such as chlorophylls, flavins, and retinol [14]. This species has a very short life in aqueous solution. It is more reactive than the stable oxygen, and it can react with polyunsaturated fatty acids (PUFA) $[13,15,16,18]$.

The role of ROS

ROS play crucial roles in human health. Under normal conditions (i.e. homeostatasis), ROS are essential for body defense against some types of bacteria strains by activated macrophages and other phagocytes in the immune system. The main source of ROS is nicotinamide adenine dinucleotide phosphate oxidases (NADPH oxidases) $[20,21]$. ROS also play a role in some 
cellular processes such as signal transduction and regulation through mediation of a number of cellular responses, such as programmed cell death [22].

Reactive oxygen species can be formed in different ways. Peroxisomes, which are involved in the catabolism of long-chain fatty acids, also are other important source of ROS in the cell. They produce the largest amount of ROS during oxidation of enzymes (NADPH oxidase, myeloperoxidases). Also, reactions that involve iron and other transition metals can be internal source of ROS. In addition to that, there are some external sources that produce free radicals or ROS, including cigarette smoke, environmental pollutants, UV light, alcohol, chemicals in food (pesticides and additives), radiation (X-rays), ozone, and certain drugs. Some researchers have indicated that a person's mental status, i.e., feelings of stress and negative emotion, as well as various conditions that result from diseases, such as inflammation, also are physiological sources for free radicals $[13,15]$.

\section{Reactivity and toxicity of ROS}

Radicals can react with other molecules in many ways; for example, a radical could donate its unpaired electron to a non-radical (a reducing radical), or could take an electron from another molecule in order to form a pair (an oxidizing radical). Another way they can react is by the combination of the unpaired electrons of two radicals to form a covalent bond. In addition, a radical could combine with a non-radical. In each of these reaction mechanisms, a non-radical becomes a radical [13]. Thus, these mechanisms can possibly lead to injuries, i.e, oxidative damage, to the cell, thereby affecting many cellular functions. If the body is unable to ward off such damage, it can lead to oxidative stress that could affect the body's DNA, proteins, and 
lipids, causing apoptosis, necrosis, and cell death [9]. In humans, oxidative stress is thought to be a key factor in the development of various diseases, including cancer, Alzheimer's, and cardiovascular diseases.

Oxygen radicals are the most important radicals generated in the living system. All scientists who have conducted research related to free radicals have indicated that, due to their high reactivity, these species can affect all important molecules of the cell [15]. Under the normal condition the body's antioxidant defence system can remove free radicals that are produced.

Lipid peroxidation (LPO): This damaging process occurs more frequently than any of the other damage process due to ROS in living organisms. It is initiated when excessive generation of ROS occurs in the cell, initiating the oxidation of lipids by extracting a hydrogen atom from a polyunsaturated fatty acid (PUFA), which is cell membrane component. The complete process of the LPO occurs in three steps, i.e., initiation, progression, and termination steps. The initiation step includes some transition metal complexes, such as Fe complex, which are essential for human body. The highly-reactive free radical, $\bullet \mathrm{OH}$, is responsible for this step, and is generated by $\bullet \mathrm{O}_{2}$ and $\mathrm{H}_{2} \mathrm{O}_{2}$. It will steal the hydrogen atoms from the unsaturated fatty acid and from the methylene carbons in the side chain of the PUFA.

$$
\begin{aligned}
& \cdot \mathrm{O}_{2} \stackrel{\text { SOD }}{\longrightarrow} \mathrm{H}_{2} \mathrm{O}_{2} \stackrel{\text { metal ion }}{\longrightarrow} \cdot \mathrm{OH} \\
& \text { Or } \mathrm{H}_{2} \mathrm{O} \stackrel{\text { lonizing radiation }}{\longrightarrow} \cdot \mathrm{OH}_{1} \mathrm{e}^{-}, \mathrm{H} \bullet, \mathrm{O}_{2}, \mathrm{H}_{2} \mathrm{O}_{2}, \mathrm{H}_{2} \\
& \mathrm{LH}+\cdot \bullet \mathrm{OH} \rightarrow \mathrm{L} \cdot+\mathrm{H}_{2} \mathrm{O} \\
& \text { (Lipid) (Lipid Alkyl radical) }
\end{aligned}
$$


After that, the oxygen with fatty acid at the carbon centered lipid radical generates ROO. The latter reacts immediately with another hydrogen atom close to the side chain of the PUFA. As a result, products of lipid hydroperoxidation will be the primary products, and they will break down into several reactive species such as lipid alkoxyl, alkanes, lipid epoxide, and fatty alcohol.

$$
\begin{gathered}
\mathrm{L} \bullet+\mathrm{O}_{2} \rightarrow \mathrm{LOO} \bullet \text { (lipid proxy radical) } \\
\mathrm{LOO} \bullet+\mathrm{LH} \rightarrow \mathrm{LOOH}+\mathrm{L} \bullet \\
\mathrm{LOOH} \rightarrow \mathrm{LO} \bullet \text { (Epoxide) }
\end{gathered}
$$

The termination step occurs when large quantities of free radical have accumulated in the cell membrane, initiating a chain reaction in which the free radicals react with each other producing non-radical species. Thus, the radical reaction will stop, and multiple peroxide molecules (as secondary products) will be produced, leading to their reacting with neighboring lipids to produce other $L \bullet$ and restarting of the chain reactions $[13,16]$.

$$
\begin{gathered}
\mathrm{L} \cdot+\mathrm{L} \bullet \rightarrow \mathrm{L}+\mathrm{L} \\
\mathrm{L} \cdot+\mathrm{LOO} \cdot \rightarrow \mathrm{LOOL} \\
\mathrm{LOO} \cdot+\mathrm{LOO} \bullet \rightarrow \mathrm{LOOL}+\mathrm{O}_{2}
\end{gathered}
$$

It is well known that ${ }^{1} \mathrm{O}_{2}$ also attacks the PUFAs by reacting with it, without stealing any hydrogen atom [lipid peroxidation]. One of the most excessive examples of end products of lipid peroxidation is malondialdehyde (MDA). Malondialdehyde is a highly toxic aldehyde and a marker for lipid peroxidation in vivo that can damage DNA leading to mutation [23].

As the peroxidation of PUFA proceeds, the fluidity of the cell membrane is decreased, leading to secondary damage to the proteins in the cell membrane. LPO takes place in the 
membrane of cytoplasm and in the mitochondria $[13,16,22]$. In fact, monounsaturated fatty acid and saturated fatty acid are more resistant to free radical due to the lesser number of double bonds with which to react with free radicals. Therefore, the more of PUFA there are in a given food, the more peroxidation will occur [24].

DNA damage: It is well known that ROS are a key factor in the initiation of cancer through damaging DNA by making some base modifications, single- or double strand break damages ( by attacking the sugar residue), deoxyribose modification, and DNA cross-linking $[25,26]$. The species $\bullet \mathrm{OH}$ is the predominant species among the ROS, and it is highly reactive. It reacts with DNA by adding $\mathrm{H}$ atom to or stealing $\mathrm{H}$ atoms from the double bond (methyl group) of any of the DNA nucleobases (adenine, cytosine, guanine, and thymine) and then generates products. The main products for the oxidative damage of DNA are 8-hydroxyguanine (8-OHG), 8hydroxyadenine (8-OH-Ade), cytocine glycol, and thymine glycol [26]. One of the most generally studied products for the oxidative damage of DNA in vivo is 8-hydroxyeoxyguanosine (8-OHdG) as shown in Figure $2[16,25]$. Deoxyguanosine could be oxidized to give $8-\mathrm{OHdG}$ or reduced to give 2,6-diamino-4-hydroxy-5-formamidopyrimidine (Fapygue). The compound 8-OHdG is stable and can combine with cytosine and adenine. DNA can be repaired of damage by DNA oxidation primarily via the DNA base-excision-repair- pathway [26]. 
<smiles>Nc1nc2c(ncn2-c2ccccc2)c(=O)[nH]1</smiles>

Deoxyguanosine<smiles>Nc1nc2c(c(=O)[nH]1)NC(O)N2O</smiles>

\section{8--.OHdG}

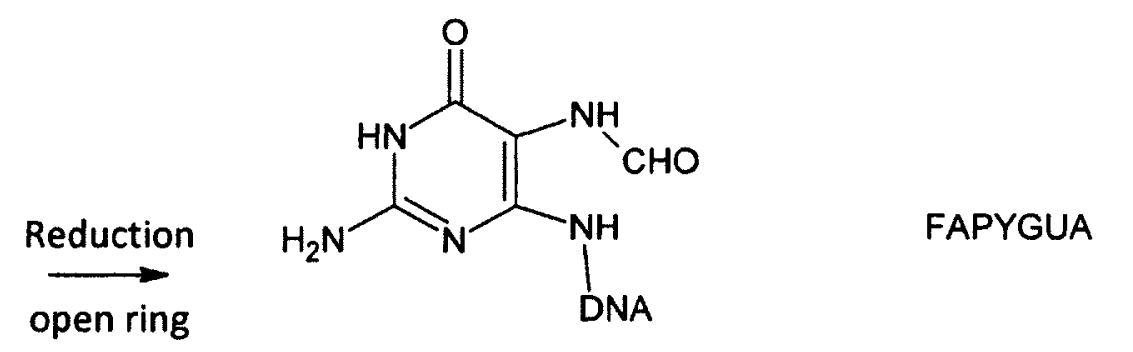

Figure 2: 8-OHdg formation by free radicals [27].

Another reaction occurs when the $\bullet \mathrm{OH}$ takes a hydrogen atom from the sugar moiety, which is released from DNA, or bound to DNA from each of the carbon atoms. Subsequently, a sugar carbon-centered sugar radical is generated, which also generates other sugar products, DNA double strand break, and base-free sites [28].

The results of these damages can be physiological such as a decrease in protein synthesis, and damage to photosynthetic proteins affecting the growth and development of the organism [7]. Several cancer research studies have found that there is a connection between the oxidation of DNA bases and cancer or inflammatory diseases such as hepatitis [29].

Protein oxidation: Proteins make up part of every cell in the body, and they have important and different roles to keep the body alive and healthy. Proteins, as any other component of the 
cell membrane, can be attacked by ROS and make some modification to their function. The protein oxidation is defined as the covalent modification of a protein induced either directly by reactive oxygen species or by-products of oxidative stress $[7,29]$. There are various types of protein oxidation modification. In all such type, the oxidation $\bullet \mathrm{OH}$ initiates the protein backbone oxidation by adding $\mathrm{H}$ atom to the aromatic ring, or abstracting $H$ atom from the aliphatic amino acid and form carbon-centered radical (RCO-). The latter reacts quickly with $\mathrm{O}_{2}$ to produce alkyl peroxide (RCOO•). This is followed by the formation of an alkoxyl radical $(\mathrm{RCO} \bullet)$, which is then converted to hydroxyl protein derivatives (RCOH) \{Reaction 1$\}$. These intermediate products may go through a side reaction with another amino acid in the same or different protein molecule. The protein-protein cross-linked derivative occurs in the absence of $\mathrm{O}_{2}$, and then the carbon-centered radical can react with another carbon-centered radical [29] \{Reaction 2\}.

1. $\mathrm{RC} \stackrel{\cdot \mathrm{OH}}{\longrightarrow} \mathrm{RC} \cdot \stackrel{\mathrm{O}_{2}}{\rightarrow} \mathrm{RCOO} \bullet \stackrel{\mathrm{HO}^{2} \rightarrow \mathrm{O}_{2}}{\longrightarrow} \mathrm{RCOOH} \stackrel{\mathrm{HO}^{2} \rightarrow \mathrm{O}^{2}+\mathrm{H}_{2} \mathrm{O}}{\longrightarrow} \mathrm{RCO} \cdot \stackrel{\mathrm{HO}^{2} \rightarrow \mathrm{O}_{2}}{\longrightarrow} \mathrm{RCOH}$ 2. $R C \bullet+R C \bullet \rightarrow R C C R$

Amino acids such as lysine, arginine, and threonine reacting with aldehyde produced during the lipid peroxidation to form of alkoxyl radicals $(\mathrm{RCO} \bullet)$ starts the step of the peptide cleavage bond, via $\alpha$-amidation or oxidation of glutamic acid, which then reacts with aldehyde, which is produced during the lipid peroxidation, to form protein carbonyl. The presence of protein carbonyl has been used as marker of the protein oxidation by ROS [29]. Several studies have established that high levels of protein carbonyl cause some diseases, such as Alzheimer's disease, diabetes, and renal failure. Therefore, carbonylation of protein cause modification in 
the peptide led to alterations in the protein function, but also show severe damage [30]. Furthermore, hydro peroxide may generate other radicals by reacting with some metal.

In addition, amino acids that contain sulfur and unsaturated bond can be more sensitive to reactive with free radicals; e.g., cysteine and methionine [19]. The other amino acids that are most reactive with free radicals are tryptophan, tyrosine, histidine, phenylalanine, and Arginine, which contain unsaturated bonds.

\section{Human antioxidant defense system}

All organisms have a defense system, i.e., antioxidant, against the process of oxidation. These antioxidants act as stabilizers to free radicals, thereby protecting cells from damage by ROS [literature review of ROS]. ROS are naturally occurring products; therefore, a number of enzymatic and non-enzymatic antioxidants mechanisms work to protect cells against ROS [31]. Interestingly, fruits, vegetables, and grains are the main source of non-enzymatic antioxidants. These sources are rich in polyphenols, carotenoids, vitamins and minerals that can prevent the oxidation [32]. When the antioxidants donate an electron to free radicals, the latter become stable and it does not react with molecules in the cell. Furthermore, because of their stability, antioxidants do not become a free radical. The imbalance in favor of the generation of free radicals over their elimination by antioxidant can result in the damages to the structure and function of macromolecules described in the previous section [33]. Inside the body, antioxidants work in three different stages:

1. Preventing damage by minimizing the formation of ROS (e.g. desferrioamine).

2. Scavenging ROS (e.g. ascorbic acid). 
3. Repairing the damaged target molecules (e.g. glutathione) [34].

Enzymatic antioxidants: To complete their catalytic activity, these enzymes require some micronutrients cofactor, such as selenium, iron, copper, and manganese. In fact, excess dietary intakes of these metals are important to complete the activity of antioxidant molecules [35].

- Superoxide dismutase (SOD):

- First-line defense due to the fact that superoxide anion is the initiation of the ROS generation.

- Lowering $\mathrm{O}_{2} \cdot-$ level.

- Converts $\mathrm{O}_{2} \bullet-$ to $\mathrm{H}_{2} \mathrm{O}_{2}[34,36]$.

- Catalase (CAT):

- Found in red blood cells and in the liver where the highest activity exists.

- Decomposes $\mathrm{H}_{2} \mathrm{O}_{2}$.

- Protects tissues from $\bullet \mathrm{OH}$.

- In the high concentration of $\mathrm{H}_{2} \mathrm{O}_{2}$, catalase acts as a catalyse $\left(\mathrm{H}_{2} \mathrm{O}_{2} \stackrel{C A T}{\longrightarrow} \mathrm{H}_{2} \mathrm{O}+\right.$ $\mathrm{O}_{2}$ ).

- In the low concentration of $\mathrm{H}_{2} \mathrm{O}_{2}$, catalase acts peroxidically (peroxidatic reaction takes place in the liver to help in alcohol metabolism) in the presence of hydrogen donor, such as phenolic compounds [20,34].

- Glutathione peroxidase (GPx):

- Is a sulfhydryl (-SH) antioxidant, which is an electron donor.

- There are eight different members in the GPx family. 
- The main function is to protect the body against damage from free radicals.

- Catalyze $\mathrm{H}_{2} \mathrm{O}_{2}$ and lipid hydroperoxides by glutathione (GSH).

- The main reaction reduces the $\mathrm{H}_{2} \mathrm{O}_{2}$ to water and Glutathione disulfide GSSG.

- GSSG converts to GSH in the presence of NADPH [37].

\section{Non-enzymatic antioxidants:}

- Vitamin E ( $\alpha$-tocopherol)

- Fat-soluble antioxidant and is a major, powerful antioxidant.

- Main function is to protect against lipid peroxidation.

- Donates hydrogen and then becomes a radical, which later reduced to its original by vitamin $\mathrm{C}[20,38]$.

- Vitamin C (Ascorbic acid)

o Water-soluble antioxidant that works in aqueous environments.

- Work well with vitamin E, carotenoids, and enzymatic antioxidants.

- Main function is to protect the thiol group of proteins from oxidation as a chain-breaking antioxidant $[20,38]$.

- Reduced glutathione (GSH)

- A tripeptide, most important intracellular free thiol and antioxidant.

- Multifunctional antioxidant.

- The main function is when it acts as a co-factor for several detoxifying enzymes.

- Also directly scavenges $\bullet \mathrm{OH}$ and ${ }^{1} \mathrm{O}_{2}$.

- Regenerates vitamin $\mathrm{E}$ and $\mathrm{C}$ back to their active forms $[20,38]$.

- Ubiquinone or Coenzyme Q 
- Also known as (Q10, CoQ10, and CoQ).

- Present in the mitochondria.

- Energy carrier then undergoes oxidation-reduction reactions.

- Inhibits lipid peroxidation by preventing the production of lipid peroxyl radicals.

- Prevents oxidation of bases and protein.

- Generates other antioxidants, such as vitamin $E[20,39]$.

\section{Dietary antioxidant compounds}

There are several groups of antioxidant molecules in food amongst them are polyphenols. They are one of the main groups of phytochemical antioxidants that occur naturally in the plants as secondary metabolites. They are found in fruits, vegetables, cereals, dry legumes, and chocolates [40]. They are characterized by at least one aromatic ring bearing with at least one or more hydroxyl substituent [40]. The antioxidant properties of these compounds may be through radical scavenging preventing thereby ROS damage or through binding iron to prevent the generation of ROS, which results from the hydroxyl group attached to the aromatic ring [anti of poly]. Phenolic compounds classified into groups based on the number of carbons on the molecule (Fig 2). They range from simple phenols to more complex compounds, which are known as polyphenols. There are more than 8000 different known structure from these substances $[40,41]$.

Phenolic compounds play a crucial role in the plants, by protecting against UV light, pathogens, and insect pests $[40,41]$. Some phenolic compounds contribute to the plant color, taste, and odor [40]. 
A number of these phenolic compounds have been identified in cereals including oat which is the subject of the current investigation.

\section{Oat and its nutrients}

Oat and other cereals are one of the important ingredients in human nutrition because they are a source of carbohydrate, lipids and proteins [8]. In addition, they also provide the body with dietary fiber, vitamins, minerals and bioactive compound with essential health benefits [42]. Epidemiological studies have shown that high consumption of whole grain cereal products reduces the risk of some chronic diseases such as obesity, diabetes, and cardiovascular diseases [43].

The major cereals consumed worldwide are wheat, rice, maize, barley, oats, rye, millet, and sorghum. Oat (Avena sativa) is consumed in relatively low quantities, but it is consumed as a whole grain [3]. Oat belongs to one of the old crops with multifunctional uses for human consumption, livestock feed and raw material for food, healthcare products and cosmetics [4]. It is an annual plant like the other cereals. However, it is the only cereal that can grow in the cool areas of Canada, the U.S.A, Russia, Poland and Germany [1].

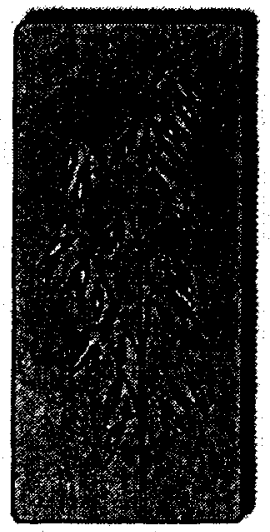

Oigss Enayelopundis Bert anios, in

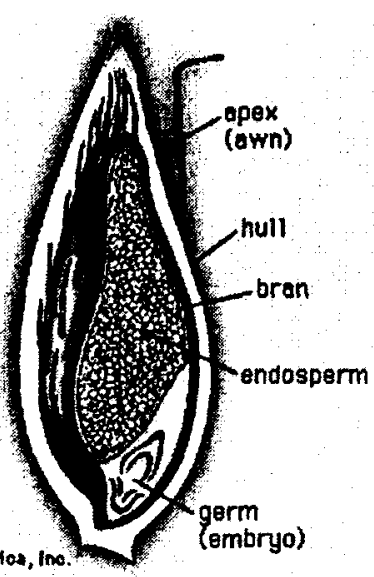

Figure 3 Oat anatomy $[43, a]$ 
The oat grain is surrounded by the kernel, which is enclosed by a hull. When the hull is removed in the milling processes, oat groat is produced, which is considered to be the whole grain oat [44]. Oat groat contains some of the oat nutrients, such as $\beta$-glucan. The outer layer of the kernel is called bran which is edible and recovered by grinding clean groats. Oat bran contains most of the oat nutrients as shown in Table1.

\section{Table 1 oat nutrients}

\begin{tabular}{|c|c|}
\hline Component & $/ 100 \mathrm{~g}$ \\
\hline \multicolumn{2}{|l|}{ Dhatels } \\
\hline Carbohydrates & $66.2 \mathrm{~g}$ \\
\hline \multicolumn{2}{|l|}{ ant } \\
\hline Dietary fiber & $15.4 \mathrm{~g}$ \\
\hline \multicolumn{2}{|l|}{ 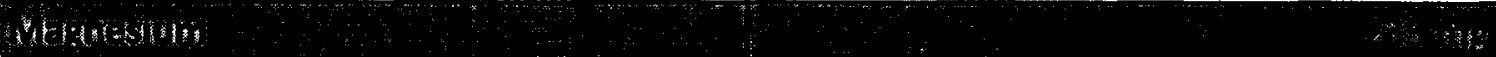 } \\
\hline Iron & $5.4 \mathrm{mg}$ \\
\hline Mhan!?: & 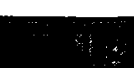 \\
\hline
\end{tabular}

\section{Oat nutrients}

Carbohydrates make up $90 \%$ of oat [45]. The main component is starch. Also, the main starches in oat are amylose and amylopectin. Also, oat contains other non-starch 
polysaccharides that contribute components of the dietary fiber, such as $\beta$-glucan, arabinoxylan and cellulose [44].

Some studies of oat and other cereals found that, among the tested cereals, oat contained the highest amount of proteins and amino acid due to the storage of proteins in the globulins.

Oat also has higher lipid content than other cereal grains. The main lipid found in oat is triglyceride, with some amounts of phospholipids, and sterols [44]. The dominant triglycerides in oat are the unsaturated fatty acids, linoleic acid and oleic acid [44]. Oat is a good source of linoleic acid, which is essential in the human diet for improving the immune system and preventing heart disease [45].

Dietary fibers are one of the essential requirements for the human digestion system, and they are found only in plants. One of the important soluble fibers that is found in oat is $\beta$ glucan [46]. It is found in higher concentration in the oat bran than the oat endosperm. The great function and nutritional properties is the high viscosities in low concentrations. Many in vivo studies have confirmed that diets containing oat $\beta$-glucan can lower LDL cholesterol, leading to reduced risk of heart diseases. Also, it was found that oat $\beta$-glucan can lower serum glucose concentrations after a meal, which suggests that this substance can help control type II diabetes. B-glucan has been used in personal care products, and pharmaceutical products due to its ability to facilitate the healing of wounds and to protect and moisturize skin [4]. 
Tocols, which include tocopherols (vitamin E) and tocotrienols occur naturally in grains including oats. Vitamin $E$ acts as an antioxidant in cells, where it protects lipids. It exist in high concentrations in oats. In addition to their scavenging properties, tocopherols can also lower LDL cholesterol by inhibiting the biosynthesis of cholesterol.

Avenanthramides (AV) phenolic compounds unique to oats have strong antioxidant capacities [3]. AVs consist of hydroxycinnamic acids linked to anthranilic acids by an amide bond [4]. In oat, avenanthramides are formed from three major phenolic acids which are, $p$ coumaric acid, caffeic acid and ferulic acid [4]. Twenty five AVs have been identified in oats. They differ in the cinnamic and anthranilic acid ring substitution. The three major acids that occur at high concentrations are AV-A, AV-B and AV-C. Studies have reported that there is a relationship between the presence of $A v$ and anti-inflammatory properties.<smiles>Cc1ccc(NC(=O)/C=C/c2ccc(O)cc2)c(C(=O)O)c1</smiles>

Figure 4 : Avenanthramide-A chemical structure.

Oats also contain small quantities of phenolic acids, and they are considered excellent nutrients for human health, and they can lower the risk of some diseases. Studies of oat have found that the major phenolic acids are hydroxybenzoic and hydroxycinnamic derivatives. Ferulic, caffeic, p-coumaric and vanillic acids are found in free form or bound to 
polysaccharides, proteins and esters in the wall of the cell. These phenolic acids may give oats their characteristic flavor [3].<smiles>O=C(O)/C=C\c1ccc(O)c([N+](=O)[O-])c1</smiles><smiles>O=C(O)/C=C\c1ccc(O)c(O)c1</smiles>

\section{Caffeic acid}

Ferulic acid

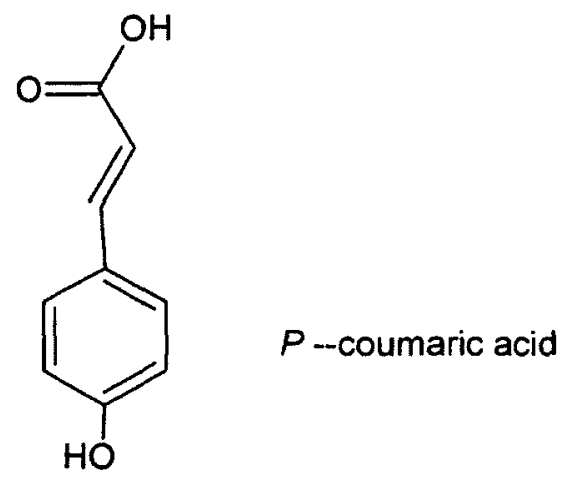<smiles>COc1cc(C(=O)O)ccc1O</smiles>

Vanillic acid

Figure 5 : some of the phenolic acids that are found in oats

Flavonoids are found in small quantities in oat, and the dominant member of flavonoids family is flavones $[3,47]$. 
<smiles>O=c1cc(-c2ccc(O)cc2)oc2cc(O)cc(O)c12</smiles>

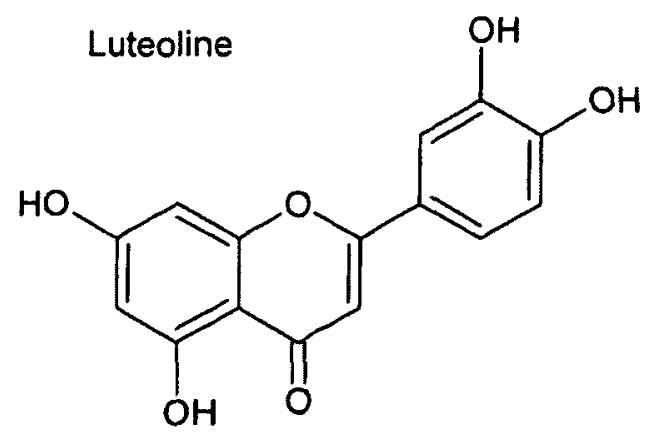

Figure 6 some of the flavones that are found in oats

Lignan is one of the family members of the phytoestrogen class; lignans are found in oats, and they also have antioxidant activity [47]. Generally, the two major lignans that are found in cereal and oat are secoisolariciresnol and matairesinol, which are converted to mammalian lignan by a microbial enzyme in the colon [42]. Epidemiological studies have reported that lignans from other foods reduced the risk of some diseases, especially breast cancer and prostate cancer [48].<smiles>COc1cc(CC(CO)C(CO)c2cccc(O)c2OC)ccc1O</smiles><smiles>COc1cc(C[C@@H]2C(=O)OC[C@H]2Cc2ccc(O)c(C(C)C)c2)ccc1O</smiles>

Figure 7: lignan chemical structure 
Phytic acid is myoinositol hexa-phosphoric acid (IP6), which serves to store the phosphorus that is found in many plants, especially in the bran [49]. It has antioxidant properties, and chelates various elements, including $\mathrm{Zn}, \mathrm{Fe}, \mathrm{Ca}$ and /or $\mathrm{Mg}$ [42]. The positive effect of phytic acid is that it reduces the incidence of colon cancer according to the results of in vitro studies [49].<smiles>O=P(O)(O)OC1C(OP(=O)(O)O)C(OP(=O)(O)O)C(OP(=O)(O)O)C(OP(=O)(O)O)C1OP(=O)(O)O</smiles>

Figure 8: Phytic acid chemical structure

More than 50 clinical studies of oat have shown that oat is a reducing agent for cholesterol and cardiovascular diseases and the effect has been attributed to beta-glucan, higher polyunsaturated fatty acids relative to other cereals, and polyphenols $[46,50]$.

\section{Extraction methods for polyphenols in cereals}

Studies of various cereals have found that phenolic compounds are more concentrated in the outer layer of the kernel, i.e., the bran [51]. In plants, phenolics are mostly bound to diverse cell components, or they are cross-linked with polysaccharides in the walls of the cells, such as pectins and arbinoxylans [52]. Phenolics compounds present in simple and soluble forms, 
constitute a small amount stored in the vacuoles. The extraction of these phytochemical compounds is the first step in determining their function.

The extraction of phenolics compounds that are stored in the vacuoles in the plant matrix is simple, just requiring the use of a common organic solvent [53]. However, the extraction of insoluble phenolic compounds is difficult because they are bound to carbohydrates and proteins. Compounds in flours are generally solubilized using mixtures of alcohol and water. Phenolic compounds are then successfully extracted by liquid-liquid procedure with solvents such ethyl acetate. Factors that affect the extraction procedure are temperature, $\mathrm{pH}$, and the ratio of the solvent to the sample [54]. Some additional steps are used during the extraction process to facilitate the removal of unwanted phenolic compounds or non-phenolic substances, such as fat.

The two main techniques used to separate and release phenolic acids are acid hydrolysis and saponification or base hydrolysis $[53,54]$. Acid hydrolysis involves the use of $\mathrm{HCl}$ and an alcohol as a solvent, such as methanol at $100{ }^{\circ} \mathrm{C}$. Saponification requires the use of $\mathrm{NaOH}$ solution at room temperature. Another less common technique is the use of enzymes. The enzymes release phenolic acids by degrading the linkage between the acids and the carbohydrates to which they are attached. 


\section{Enzymes activity}

Enzymes are used in industry to bring about reactions at normal temperature and pressure. The most common enzymes that are used in food processing are proteases and carbohydrases $[54, a]$.

Carbohydrases are hydrolytic and digestive enzymes that break down the complex carbohydrates to simpler molecules, such as glucose. These enzymes are found in the mammalian intestine $[54, a]$.

Each enzyme has its own specificity against certain bonds. For example, $\alpha$-amylase and amyloglucosidase belong to the amylase group. Amyloglucosidase cleave the $\alpha-1,4$ and $\alpha-1,6-$ glycosidic bonds. On the other hand, $\alpha$-amylase hydrolysis the $\alpha$-1,4-glucan linkages in polysaccharide, such as starch. Cellulase hydrolyse the $\beta-1,4-$ glycosidic linkage in cellulose and cereal $\beta$-D-glucan $[54, b]$. However, Viscozyme is a multi enzyme complex containing a wide range of carbohydrases, including arabanase, cellulase, $\beta$-glucanase, hemicellulase and xylanase. It is used to degrade non-strach polysaccharides as branched pectin-like substances found in plant cell wall. Also, it reduces viscosity of such material $[54, c]$. 


\section{Chapter 3: Methodology}

\section{Material and chemicals}

Oat flour was donated by Can-Oat Milling (Portage La Prairie, Manitoba MB). 2,2'-azobis (2methylpropionamidine) dihydrochloride (AAPH), mono- and dibasic potassium phosphates, 6hydroxy-2,5,7,8-tetramethylchroman-2-carboxylic acid (Trolox), rutine trihydrate, 1,10phenanthraline, gallic acid, $\alpha$-tocopherol, ferrozine, ethylene diamine tetraacetate (EDTA), iron(II) fluoride, cobalt (II) fluoride tetrahydrate, picolinic acid (PA), propyl gallate, magnesium sulfate, trans-cinnamic acid, caffeic acid, vanillic acid, p-coumaric acid, alpha-amylase $(110,000$ units/g), cellulase (100 Fungal Beta-glucanase (FBG)/g), viscozyme (700 Endo-Glucanase Units (EGU)/g), amyloglucosidase $(70,000$ Units/g), and $30 \%$ hydrogen peroxide were obtained from Sigma-Aldrich Ltd (Oakville, ON, Canada). ASC and HPLC grade methanol, ethylacetate, hexanes, and fluorescein were purchased from Fisher Scientific Co. (Nepean, ON, Canada). High-purity water was produced in the laboratory by an Alpha-Q system (Millipore, Marlborough, MA).

\section{Preparation of phenolic extracts}

The medium oat bran flour samples from Can-Oat $(5 \times 50 \mathrm{~g})$ were defatted by mixing with hexane $(1: 4 \mathrm{w} / \mathrm{v})$ and mixed for $1 \mathrm{~h}$ with a magnetic stirbar. The samples were then filtered on Whatman paper No. 1 and the defatted flours were dried overnight in a fume hood. To each defatted sample $300 \mathrm{ml}$ of doubled distilled water were added and the $\mathrm{pH}$ was adjusted to a value where the enzyme should remain active; the enzymes were added in the amount shown in Table 1 . Samples were first extracted by incubation at $50^{\circ} \mathrm{C}$ for $2 \mathrm{~h}$ in an incubator shaker (200 rpm) model G25 from New Brunswick (Edison, NJ, USA). The pH was then adjusted to 7.0 
and $300 \mathrm{ml}$ of methanol was added to each sample and incubated for $30 \mathrm{~min}$ at $50^{\circ} \mathrm{C}$. The extracts were recovered after centrifugation at $4000 \mathrm{~g}$ in a Thermo Sorval centrifuge model XTR centrifuge from Fisher Scientific Canada (Nepean, ON), filtration on Whatman paper No. 1 and dried on anhydrous magnesium sulphate. The solvent was removed using Heidolph Laborota 4000 rotary evaporator model (Fisher Scientific Canada, Nepean, ON) at $40{ }^{\circ} \mathrm{C}$. The samples designated as water-methanol extracts were recovered in pure water and freeze dried (Freezone $4.5 \mathrm{I}$, Labconco Co., Kansas City, MO), and stored at $20^{\circ} \mathrm{C}$ until further analyses. To obtain ethylacetate (EtOAc) extracts, $0.5 \mathrm{~g}$ of freeze dried water-methanol sample was dissolved in $4 \mathrm{ml}$ of water $(\mathrm{pH} \mathrm{2),4} \mathrm{ml}$ of EtOAc was added and vortexed for $1 \mathrm{~min}$. The extraction was repeated three times and the combined EtOAc fractions dried under a stream of nitrogen gas at $40^{\circ} \mathrm{C}$ in brown tubes for determination of antioxidant and antimicrobial activity and total phenolic content.

Table 2 Extraction condition of medium oat bran samples

\begin{tabular}{|c|c|c|}
\hline Sample $(50 \mathrm{~g})$ & pH & Enzyme amount \\
\hline 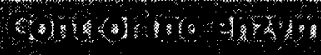 & & \\
\hline Viscozyme & 4.6 & $200 \mathrm{FBG}$ \\
\hline 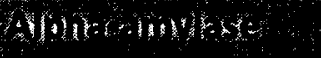 & & 2. \\
\hline Celluclase & 5.5 & $3000 \mathrm{EGU}$ \\
\hline hollowlangloryo & 88 & 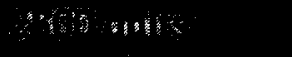 \\
\hline
\end{tabular}

FBG: fungal beta-glucanase units: 1 FBG of viscozyme $L$ is the amount of enzyme required under standard

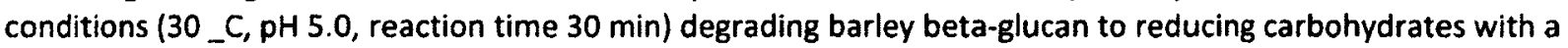
reduction power corresponding to $1 \mathrm{mM}$ glucose/min. EGU: endoglucanase units. 1 EGU indicates the amount of celluclase which liberates. 1 uM reducing sugar from $1 \%$ carboxymethyl cellulose at pH 5.0 and 50 _C. 


\section{Determination of total phenolic content (TPC)}

The water-methanol extracts were dissolved in methanol to obtain a concentration of 0.5 and $1.0 \mathrm{mg} / \mathrm{ml}$. To facilitate the dissolution, samples were sonicated for $1 \mathrm{~min}$ in a sonicator model FS30 (Fisher Scientific Canada). The TPC was determined according to literature $[55,56]$ with some modifications. Folin-Ciocalteu's reagent $(0.5 \mathrm{ml})$ was added to centrifuge tubes containing $0.5 \mathrm{ml}$ of methanolic extracts. The contents were mixed thoroughly, and $4 \mathrm{ml}$ of sodium carbonate $(75 \mathrm{~g} / 1)$ were added to each tube. To the mixture, $5 \mathrm{ml}$ of distilled water were added with thorough mixing. The tubes were then allowed to stand for $2 \mathrm{~h}$ at ambient temperature in the dark, and subsequently the contents were centrifuged for $5 \mathrm{~min}$ at $3500 \mathrm{~g}$. The absorbance of the supernatant was read at $765 \mathrm{~nm}$. A blank sample prepared with $0.5 \mathrm{ml}$ of methanol in place of the sample solution was used for background subtraction. Total extracted phenolics were expressed as milligrams of gallic acid equivalents (GAE)/g of bran material using a standard curve prepared with $12.5-200 \mu \mathrm{g} / \mathrm{ml}$ (final concentrations) of gallic acid.

\section{Antioxidant activity assays}

\section{Determination of oxygen radical absorbance capacity (ORAC)}

This assay was performed according to reported procedures [57]. A microplate fluorescence reader model FLx800 (Bio-Tek Instruments, Inc., Winooski, VT) with fluorescence filters (excitation wavelength $485 / 20 \mathrm{~nm}$, emission wavelength $528 / 20 \mathrm{~nm}$ ) was used and run using the Gen5 $5^{\mathrm{TM}}$ software. Potassium phosphate buffer $(75 \mathrm{mM}, \mathrm{pH} 7.4)$ was used to prepare all reagents, standards, samples, and the control. Five Trolox (6-hydroxy-2,5,7,8- 
tetramethylchroman-2-carboxylic acid ) concentrations, $6.25,12.5,25,50$ and $100 \mu \mathrm{M}$, were used for the standard. Fluorescein $(0.082 \mu \mathrm{M})$ and AAPH $(0.15 \mathrm{M})$ were prepared immediately before use. Rutin trihydrate $(10 \mu \mathrm{M})$ was used as control. Two concentrations, 150.0 and 300 $\mu \mathrm{g} / \mathrm{ml}$ water-methanol extract; and 13.0 and $26.0 \mu \mathrm{g} / \mathrm{ml}$ for ethyl acetate extracts, were used in triplicate. Fluorescein $(120 \mu l)$ was transferred into the wells followed by addition of $20 \mu l$ of samples or blank (buffer). The mixture was incubated for $20 \mathrm{~min}$ at $37^{\circ} \mathrm{C}$ in the built-in incubator, and subsequently APPH solution $(60 \mu \mathrm{l})$ was added to each well. Data were collected every min for a total of $50 \mathrm{~min}$ and processed according to $[58,59]$. The ORAC values were expressed as Trolox equivalents (TE) using the standard curve.

\section{Determination of Hydroxyl Radical Averting Capacity (HORAC)}

This assay was performed according to reported procedure [60] with some modification. Briefly, potassium phosphate buffer $(75 \mathrm{mM}, \mathrm{pH} 7.4)$ was used to prepare all standards, samples, and controls. Five Propyl gallate concentrations $3.125,6.25,12.5,25$ and $50 \mu \mathrm{M}$ were used to make standard curve and a solution of $1.53 \mathrm{mM}$ cobalt (II) solution was prepared by adding $5.2 \mathrm{mg} \mathrm{CoF} 2.4 \mathrm{H}_{2} \mathrm{O}$ and $6.7 \mathrm{mg}$ of picolinic acid to $6.7 \mathrm{ml}$ of water. Fluorescein 10.1033 $\mu \mathrm{M}$ in buffer), $\mathrm{H}_{2} \mathrm{O}_{2}(0.37 \mu \mathrm{M}$ in water) were also prepared as well as rutin trihydrate (50 and $100 \mu \mathrm{M})$ and caffeic acid $(125 \mu \mathrm{M})$ standards. Samples were analyzed in triplicate at 0.10 and $0.05 \mathrm{mg} / \mathrm{g}$ bran. For the assay, $0.1033 \mu \mathrm{M}$ fluorescein $(120 \mu \mathrm{l})$ was transferred into a black microplate followed by addition of $20 \mu \mathrm{l}$ of samples or blank (buffer). The plates were incubated for $10 \mathrm{~min}$ at $37^{\circ} \mathrm{C}$, and then add $30 \mu \mathrm{l}$ hydrogen peroxide and $30 \mu \mathrm{l}$ of cobalt (II) fluoride solution were added. Data were collected every min for a total of $35 \mathrm{~min}$ with a microplate fluorescence reader model FLx800 with fluorescence filters (excitation 485/20 nm, 
emission $528 / 20 \mathrm{~nm}$ ) controlled by Gen5 ${ }^{\text {TM }}$ software was used (Bio-Tek Instrument, Inc., Winooski, VT). HORAC values were expressed as propyl gallate equivalents (PGE)/g bran.

\section{Hydroxyl radical (HO•) scavenging assay}

The HO scavenging assay was modified on the basis of a reported procedure [61]. Methanol-water extracts equivalent to $10 \mathrm{mg}$ of $\mathrm{bran} / \mathrm{ml}$, negative control and gallic acid 0.5 $\mathrm{mg} / \mathrm{ml}$ (positive control) were prepared in $0.75 \mathrm{mM}$ potassium phosphate buffer at $\mathrm{pH} 7.4$. Then, $300 \mu$ l of each solution were added to 1.5 microcentrifuge vials in triplicate followed by the addition of $300 \mu \mathrm{l}$ of $3 \mathrm{mM}$ 1,10-phenanthroline in phosphate buffer and $300 \mu \mathrm{l}$ of $3 \mathrm{mM}$ $\mathrm{FeSO}_{4} 7 \mathrm{H}_{2} \mathrm{O}$ in water. To initiate the reaction, $300 \mu \mathrm{l}$ of $0.03 \%$ aqueous $\mathrm{H} 2 \mathrm{O} 2$ were added, and the reaction mixture was incubated at $37^{\circ} \mathrm{C}$ for $1 \mathrm{~h}$ with shaking at $200 \mathrm{rpm}$ on a Max-Q 500 incubator (Fisher Scientific Canada, Nepean, ON). The absorbance was measured at $536 \mathrm{~nm}$ using a Cary 50 Bio UV-Vis spectrophotometer controlled by Cary WinUV Bio Pack Software (Varian Inc., Mississauga, ON). The absorbance was also determined for a blank (without sample and $\mathrm{H} 2 \mathrm{O} 2$ ) and a control (without sample). The HO- scavenging activity was calculated as described in literature [62].

\section{Superoxide scavenging activity}

The superoxide scavenging activity of water-methanol extracts and gallic acid (positive control) was measured according to previous reported method [63]. The amount of watermethanol extracts equivalent to $10 \mathrm{mg}$ of bran were dissolved in $2 \mathrm{ml}$ of $50 \mathrm{mM}$ Tris- $\mathrm{HCl}$ buffer containing $1 \mathrm{mM}$ EDTA, $\mathrm{pH}$ 8.3. Gallic acid at $0.5 \mathrm{mg} / \mathrm{ml}$ was used as control. To run the assay $500 \mu \mathrm{l}$ of sample or control were mixed with $500 \mu \mathrm{l}$ of the buffer in $1.5 \mathrm{ml}$ disposable UV cuvettes in darkness. Then, $460 \mu \mathrm{l}$ of $1.5 \mathrm{mM}$ pyrogallol dissolved in $10 \mathrm{mM} \mathrm{HCl}$ were added to 
each cuvette. The reaction rate (DA/min) was measured immediately at $420 \mathrm{~nm}$ for $4 \mathrm{~min}$ at room temperature using the buffer as a control. The superoxide scavenging activity was calculated using the following equation.

Superoxide scavenging activity $\%=\{[(\Delta A / \min ) c-\langle\Delta A / \min ) s] /(\Delta A / \min ) c\} \times 100$.

\section{Determination of free radical scavenging activity by DPPH assay}

The free radical scavenging activity of water-methanol extract of oat bran was measured by 1,1-diphenyl-2-picryl-hydrazil (DPPH•) according to the literature [61] with some modification. Briefly, $200 \mu \mathrm{l}$ of each sample solution at 1.0 and $0.5 \mathrm{mg} / \mathrm{ml}$ in $50 \%$ aqueous methanol were added to $800 \mu$ l of $100 \mu \mathrm{M}$ DPPH prepared in $100 \%$ methanol. The mixtures were incubated for $30 \mathrm{~min}$ at room temperature at absorbances recorded at $515 \mathrm{~nm}$ on a Cary 50 Bio UV-Vis spectrophotometer controlled (Varian, Mississauga, ON). A methanolic solution of DPPH served as a control. A lower absorbance represents a higher DPPH scavenging activity. Percentage inhibition was calculated using the following formula:

$$
\text { Scavengingeffect }(\%)=\left(1-\frac{A_{s}}{A_{c T L}}\right) \times 100
$$

Where $A_{s}$ was the absorbance at time $t$ and $A_{C T L}$ the absorbance of control (DPPH) at time zero.

\section{Metal chelating assay}

The metal chelating assay was based on a previous method [64] with slight modifications. An aliquot $(1 \mathrm{ml})$ of water-methanol extract sample or gallic at a final concentration of 0.5 or 1.0 $\mathrm{mg} / \mathrm{ml}$ was combined with $50 \mu \mathrm{l}$ of $\mathrm{FeCl} 2$ solution $(2 \mathrm{mmol} / \mathrm{l})$ and $1.85 \mathrm{ml}$ of double-distiled water. Ferrozine (3-(2-pyridyl)-5,6-diphenyl-1,2,4-triazine-40,400-disulfonic acid sodium salt) solution (100 $\mu \mathrm{l}, 5 \mathrm{mM})$ was added and mixed vigorously. The mixture was left to stand at room 
temperature for $10 \mathrm{~min}$. The absorbance was measured at $562 \mathrm{~nm}$ using a Cary 50 Bio UV-Vis spectrophotometer controlled by Cary WinUV Bio Pack Software (Varian Inc., Mississauga, ON). In the control, the sample was replaced with double-distilled water. The chelating effect was calculated by the following equation:

$$
\text { Chelating effect }(\%)=(A c-A s / A c) \times 100
$$

\section{Inhibition of linoleic acid autoxidation}

Linoleic acid oxidation was measured according to the method of [65] with some modification. Phenolic extracts equivalent to $1 \mathrm{~g}$ bran of each sample were dissolved in $50 \mathrm{mM}$ phosphate buffer ( $\mathrm{pH} \mathrm{7.0)}$ and further diluted 5 and 10 times. Assay was performed by adding $0.8 \mathrm{ml}$ of each sample to $0.8 \mathrm{ml}$ of linoleic acid $(10.8 \mathrm{mg} / \mathrm{ml}$ in $95 \%$ ethanol) in $2.0 \mathrm{ml}$ microcentrifuge vials, and at $60^{\circ} \mathrm{C}$ incubated for 6 days. The amount of oxidation was evaluated daily by measuring the ferric thiocyanate values as follows. The sample solution (50 $\mu$ ) incubated in the linoleic acid model system described above was mixed with $2.35 \mathrm{ml}$ of $75 \%$ ethanol, $50 \mu \mathrm{l}$ of $30 \%$ ammonium thiocyanate, and $50 \mu \mathrm{l}$ of $0.02 \mathrm{~mol} / \mathrm{L}$ ferrous chloride solution in $3.5 \% \mathrm{HCl}$. Then, the thiocyanate value was measured by reading absorbance at $500 \mathrm{~nm}$ on a Cary 50 Bio UV-Vis spectrophotometer controlled by Cary WinUV Bio Pack Software (Varian). $\alpha$ tocopherol was used as a control. The degree of color development represented linoleic acid oxidation.

\section{Extraction of phenolic acids for HPLC analysis}

The extraction procedure was done according to literature [66] with some modification. An aliquot of the water-methanol extract, equivalent to $0.5 \mathrm{~g}$ bran of each sample was dissolved in $6 \mathrm{ml}$ of acidified water $(\mathrm{pH} \mathrm{2})$ and partitioned with $4 \mathrm{ml}$ of ethyl acetate three times. After 
centrifugation to break any emulsion, the combined ethyl acetate layers containing free phenolic acids (FPA) were dried under a stream of nitrogen gas. The water phase was neutralized to $\mathrm{pH} 7$ with $2 \mathrm{M} \mathrm{NaOH}$ and was freeze-dried (Freezone $12 \mathrm{~L}$, Labconco, Kansas City, MO). The dried sample was dissolved in $4 \mathrm{ml}$ of $2 \mathrm{M} \mathrm{NaOH}$ and stirred for $4 \mathrm{~h}$ at room temperature. The solution was then acidified to $\mathrm{pH} 2$ and was extracted with ethyl acetate as previously described. The ethyl acetate layers contained base-hydrolysable phenolic acids (BHPA). All FPA and BHPA samples were reconstituted in 1:1 (water: methanol) containing 1\% acetic acid, filtered through a $0.45 \mu$ m nylon syringe filter (Dima Glass, Richmond Hill, ON) prior to HPLC analysis.

\section{HPLC analysis}

HPLC analysis was carried out using Waters 1525 Binary HPLC Pump equipped with a vacuum membrane degasser, an auto sampler model 2707 with temperature control and a 2998 photodiode array detector (Waters, Milford, MA). Sample compartment was maintained at $8^{\circ} \mathrm{C}$ and data were collected and processed and analyzed using Waters Empower version 3 software. The analytical column was Waters Spherisorb $5 \mu \mathrm{m}$ ODS2 $(4.6 \times 250 \mathrm{~mm})$. The injection volume was $30 \mu \mathrm{l}$ and the flow rate was $1.0 \mathrm{ml} / \mathrm{min}$. A mixture of $1 \%$ acetic acid in water (A) and $1 \%$ acetic acid in methanol (B) was used to elute the phenolic acids from the column. The linear gradient conditions were A: B (100:0) for 5 minutes, A:B ( 80:20) for 25 min, $A: B(50: 50)$ for $5 \mathrm{~min}$, and $A: B(10: 90)$ for $5 \mathrm{~min}$. There was 10 minutes of equilibrium between injections. The peaks were monitored at $280 \mathrm{~nm}$ and identified by comparing their retention times and UV spectra with those of authentic standards. 


\section{Antimicrobial activity}

The antimicrobial activity of the phenolic extracts was determined against two microorganisms, the gram positive bacterium (Bacillus subtilis ATCC 23857), and the gram negative bacterium (Escherichia coli $\mathrm{DH} 5 \alpha$, Invitrogen, Burlington, Canada). The bacteria were maintained on Petri dishes containing tryptic soy agar (TSA; Benton Dickinson, Sparks, MD). Bacteria were transferred in tryptic soy broth (TSB; Benton Dickinson) and incubated for $48 \mathrm{~h}$ (E. coli) or for $48 \mathrm{~h}$ (B. subtilis) at $26^{\circ} \mathrm{C}$ with shaking (150 rpm). Following incubation, bacteria cells were counted using a hemacytometer and adjusted to $5 \times 10^{7}$ cells $/ \mathrm{ml} .5 \mu \mathrm{l}$ of each cell suspension were individually transferred to $450 \mu$ l of TSB. Phenolic extracts equivalent to $1 \mathrm{~g}$ of oat bran were prepared in water and diluted 100,000 times. $50 \mu \mathrm{l}$ of each extract was added to the cells cell suspensions. $5 \mu$ l of sterile water served as the control. The cell suspensions were incubated for $48 \mathrm{~h}$ at $26^{\circ} \mathrm{C}$ with shaking (150 rpm). Following incubation, samples were serial diluted and transferred to TSA dishes. The dishes were incubated at $26^{\circ} \mathrm{C}$ for $24 \mathrm{~h}$ for $E$. coli and $48 \mathrm{~h}$ for B. subtilis. Following incubation, colony forming units (CFU) per $\mathrm{ml}$ were determined for each treatment. Each sample was performed in duplicate and the experiment consisted of a complete bloc design with five repetitions. 


\section{Chapter 4: Results and discussion}

Most of the phenol compounds in oat and other cereals are bound to cell wall polysaccharides. The use of carbohydrases in this study was to see if while degrading polysaccharides, they could at the same time increase the extraction of phenolic compound and increase bioactivities specifically antioxidant and antimicrobial activities of the resulting extracts. I was also interested in quantifying the effect on the concentrations of some common phenolic acids.

\section{Polysaccharide degradation}

The 3,5-dinitrosalicylic (DNS) acid assay was used for quantification of reducing sugars, which are the sugars that have aldehyde group) in samples. The results showed that samples treated with the enzymes contained more reducing sugars than the control sample (no enzyme). The highest percentage was for viscozyme and amyloglucosidase at $21.4 \%$ and $20 \%$ respectively. Alpha-amylase had the lowest percentage among the treated samples with $12.6 \%$. The control sample had just $2 \%$ reducing sugar. As a result, carbohydrases cleaved the polysaccharides in the cell which led to release of substrates that are bound to it. The 3,5-dinitrosalicylic acid assay (DNS) method is one of the common methods to measure the amount of reducing sugar in food samples and it is based on the reduction of an oxidizing agent by the sugar. The increase of reducing sugars in samples was associated with concomitant increase in amount of other extractable compounds such as phenolic compounds as shown in the next section. Some studies showed a positive correlation between glucose release and phenolic compound in food samples treated with enzymes [67]. Kapasakalidis et al. (2009) [68] observed a degradation of cell wall polysaccharide $(6.13 \mathrm{mg} / \mathrm{ml})$ in supernatant of black currant treated with cellulase and 
this concentration was affected by both enzyme/substrate ratio and extraction time. The enzyme substrate ratios and incubation time used in the present study were selected based on available data on their use in other food samples. The concentration of vizcozyme was selected based on the work of Guan and Yao (2008) [69] who tried different concentrations and incubation times to optimise the conditions for protein extraction from oat bran. Amylase and cellulase concentrations were within the range used for protein extraction from heat-stabilised defatted rice bran [70].

Table 3 reducing sugar and total phenolic content

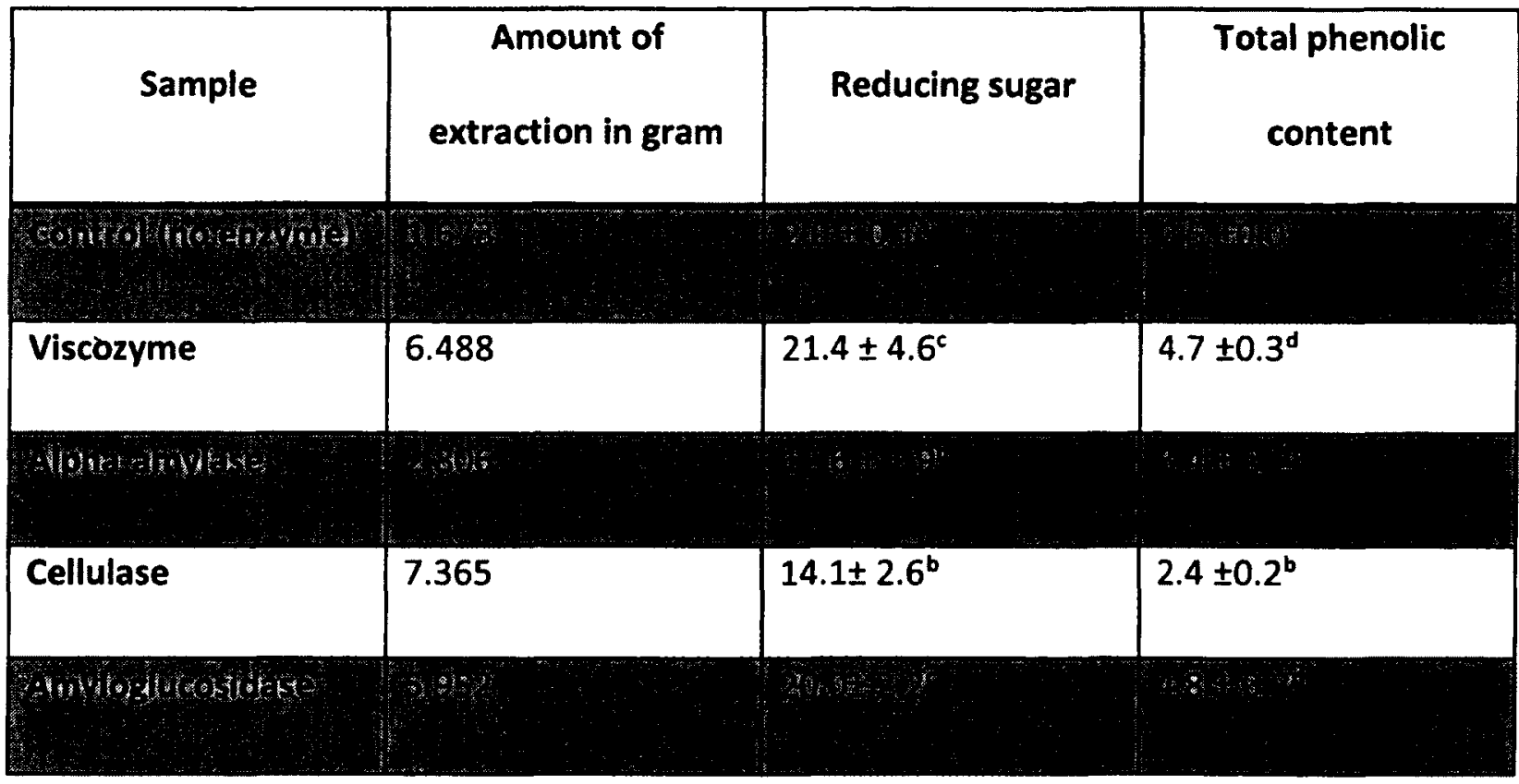

Different letters within the same column indicate significant difference $(P<0.05)$.

\section{Total phenolic content}

The enzyme addition at concentrations shown in Table 3 had a significant effect on the release of phenols in the samples obtained with water-methanol (50:50). Phenolic hydroxyl group cause a reduction to the Folin-Ciocalteu (FC) reagent, resulting in the formation of dark blue product. The control sample had total phenolic content (TPC) of $0.5 \mathrm{mg} \mathrm{GAE} / \mathrm{g}$ of bran. 
Amongst the samples, cellulase yielded the lowest TPC content $(2.4 \mathrm{mg} \mathrm{GAE} / \mathrm{g}$ ), while viscozyme and amyloglucosidase had the highest, 4.7 and $4.8 \mathrm{mg} \mathrm{GAE} / \mathrm{g}$, respectively. The analysis of TPC from 21 oat varieties of aqueous methanol extracts showed that their content range from 0.11 to $0.54 \mathrm{mg}$ ferulic acid equivalents/g of grain [71]. Although we used gallic acid as standard, the TPC of control sample is within the reported range. Emmons and Peterson (1999) [72] found that the TPC of four oat cultivars adapted to the Midwestern USA were 0.24$0.28 \mathrm{mg} \mathrm{GAE} / \mathrm{g}$. These values are lower certainly because they are expressed per gram of grain, while the results from this study are expressed per gram of bran and also because phenolic compounds are more concentrated in cereals bran. It has been reported that the TPC of oat was affected by germination. From extracts of oat samples obtained at different time during germination Tian et al. (2010) (73] reported a TPC of 0.25 to $0.91 \mathrm{mg} \mathrm{GAE} / \mathrm{g}$. The TPC of our control sample is within this range however, the TPC of all four carbohydrases pre-treated oat bran samples are higher than literature values.

\section{Oxygen radical absorbance capacity (ORAC) assay}

The ORAC is one of the standard assays accepted for measuring the antioxidative activity of nutraceuticals and functional foods, botanicals, and herbs. The fluorescein, which is protected by the antioxidant, is used as a probe to detect the antioxidant activity of the sample; therefore, the more antioxidant in the sample, the more stable fluorescence signals. The procedure has been widely used to assess the free radical scavenging capacity of pure antioxidants, protein hydrolysates, plant/food extracts, and biological fluids [74]. ORAC is the only assay that combines both inhibition time and degree of inhibition into a single quantity [75]. ORAC was used in this study (Fig. 3) to evaluate the scavenging power of aqueous 
methanol and ethyl acetate extracts from the control and carbohydrases treated oat bran samples and expressed the results as $\mu \mathrm{M}$ Trolox equivalents (TE)/g. For aqueous methanol extracts (Fig. 3A), it was found that viscozyme and cellulase treated samples were the most active with ORAC values of $24.1 \pm 4.3$ and $25.4 \pm 3.2 \mu \mathrm{M} \mathrm{TE} / \mathrm{g}$ bran, respectively. The ORAC values for alpha-amylase treated sample $(15.9 \pm 1.9 \mu \mathrm{M} \mathrm{TE} / \mathrm{g})$ and the control sample $(14.4 \pm 2.3$ $\mu \mathrm{M} \mathrm{TE} / \mathrm{g}$ ) were not significantly different. Although the ORAC values of samples are higher than the control they did not correlate with the total phenolic content suggesting that other compounds like peptides and amino acids may have contributed to the activity. As seen in Fig. 3B, ORAC values of all ethyl acetate samples were significantly higher than control. Viscozyme treated sample had the highest peroxyl radical scavenging potential with an ORAC of $505 \pm 26$ $\mu \mathrm{M} \mathrm{TE} / \mathrm{g}$. The sample resulting from alpha-amylase treatment displayed the lowest activity (220 $\pm 10 \mu \mathrm{M} \mathrm{TE} / \mathrm{g})$. Overall, the antioxidant properties of ethyl acetate extracts are higher than those of the corresponding aqueous methanol extracts. This is because treating oat bran extract with cell wall degrading enzymes produces more free phenols that can be separated from sugars molecules by extraction with ethyl acetate. The difference in the radical scavenging properties of samples could be due to the enzymes selectivity and variation in the reaction rates [76]. It was found that hydroxybenzoic, hydroxycinnamic, flavonols, flavones, and stilbenes concentration in lentils varied upon treatment of flour with various enzymes (phytase alpha galactosidase, viscozyme, and tannase) [77]. Handelman et al. (1999) [78] found that the ORAC values of oat varied from 2.08 to $8.13 \mu \mathrm{M} \mathrm{TE} / \mathrm{g}$. These authors also reported that the bran and flour had similar antioxidant activities, due to the mixing of the bran with the starchy endosperm. The higher value found in this study for our control bran sample $(14.4 \pm 2.3 \mu \mathrm{M}$ 
$\mathrm{TE} / \mathrm{g}$ ) is probably due to the fact that we used water-methanol at $50^{\circ} \mathrm{C}$ compared to $100 \%$

methanol used by [78]. The antioxidant activity of two pearled Canadian wheat cultivars

Western Amber Durum and Western Red Spring ranged from 41 to $87 \mu \mathrm{M} \mathrm{TE} / \mathrm{g}$ of defatted

materials [79]. The wheat appeared to have a superior antioxidant activity than oat in the ORAC assay.
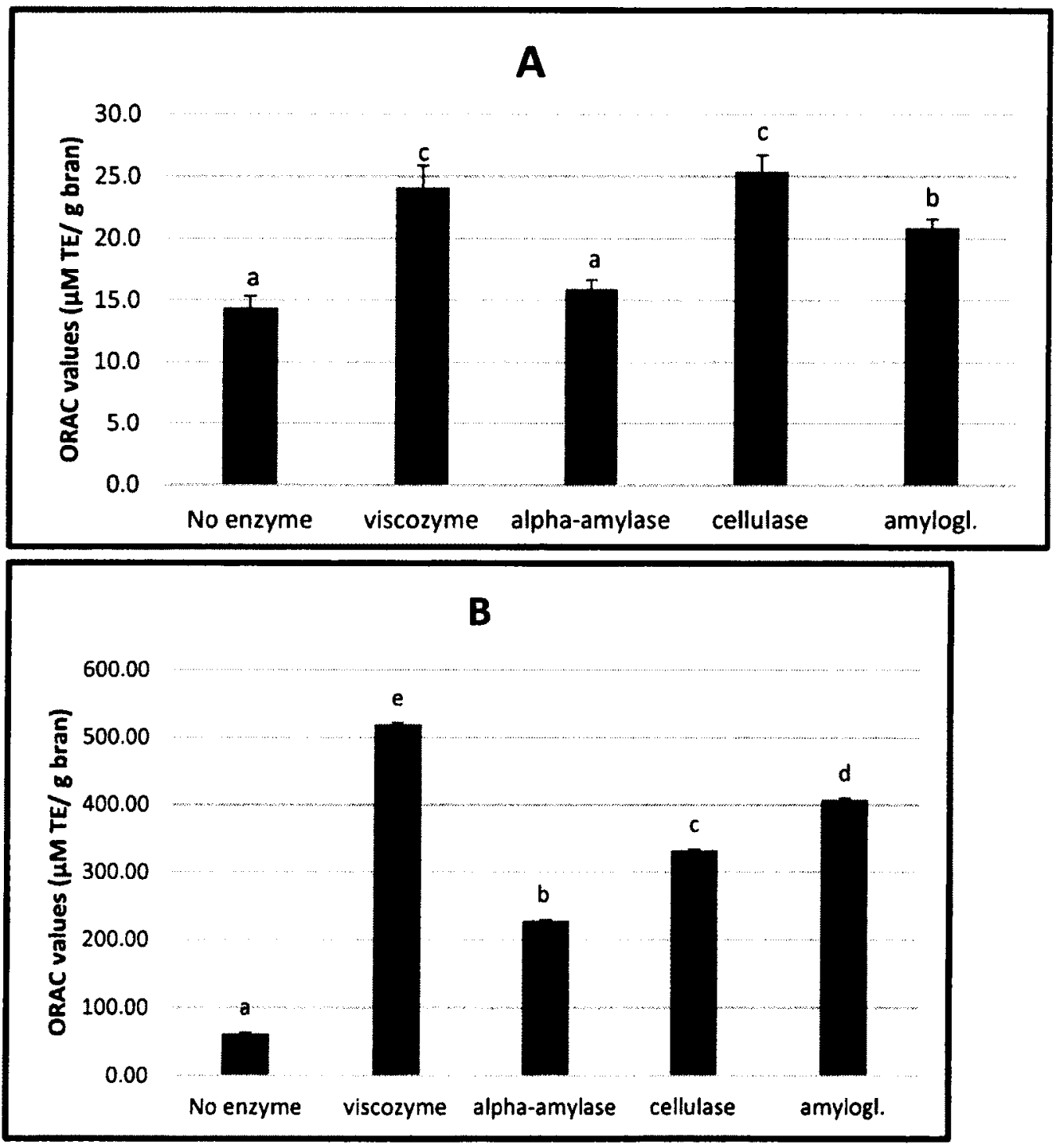

Figure 3: ORAC values of control and carbohydrases treated samples. (A) samples obtained with methanol-water (50:50). (B) ethyl acetate extracts obtained after partition with watermethanol extracted samples in (a). Values are mean \pm SD $(n=3)$. Amylogl:: amyloglucosidase. Different letters indicate significant difference $(P<0.05)$ 


\section{Hydroxyl Radical Antioxidant Capacity (HORAC) and Hydroxyl radical}

\section{scavenging activity}

Hydroxyl radicals $(\mathrm{HO} \cdot)$ are highly reactive and can be formed from superoxide anion and hydrogen peroxide, in the presence of metal ions, such as copper or iron which is called Fenton reaction. When a hydroxyl radical reacts with aromatic compounds, it can formed hydroxylcyclo-hexadienyl radical that can undergo further reactions with oxygen to give peroxyl radical, or decompose to phenoxyl-type radicals by water elimination [80]. Due to the fact that HO radicals are short lived with a high rate constant, it is unlikely that antioxidants present at biological concentrations will be able to scavenge the HO radical [81]. However, antioxidants that are able to chelate metal may be able to prevent the formation of the HO radical, thus acting as a preventative antioxidant [82]. The HORAC and hydroxyl radical scavenging assays therefore measure the ability of the antioxidant present to chelate Co (II) prior to the occurring of Fenton reaction [59].

The HORAC assay is based on the oxidation of fluorescein by hydroxyl radical through a classic hydrogen atom transfer. HORAC values of oat bran samples are presented in Figure 4. Values ranged from 13.3 to $20.1 \mathrm{PGE} / \mathrm{g}$ of bran. Amyloglucosidase increased HORAC value by approximately $30 \%$ relative to the control. Viscozyme and cellulase showed the highest increases in HORAC values (approximately $51 \%$ ) when compared to the control. There was however no significant difference between alpha-amylase and control samples. Because HORAC measures the metal chelating and DPPH scavenging properties, the results from these two assays are not necessarily similar [82]. However, HORAC data from this study seem to follow to the same trend as those from the DPPH assay. Other studies have shown that phenolic 
compounds can reduce the generation of $\mathrm{HO} \cdot$ radicals [81]. The HORAC value of control oat bran sample from the present investigation is within the range of those determined for aqueous methanolic extracts from barley cultivars (9.1 and $13.0 \mathrm{CAE} / \mathrm{g})$ [55]. It has been reported that phenolic compounds with metal chelation potentially show higher HORAC FL values, whereas the compounds with poor metal chelation activity show negligible HORAC values [82]. Phenolic compounds act as metal chelators by coordination to Co(II), thereby blocking the reaction sites for $\mathrm{H}_{2} \mathrm{O}_{2}$. HORAC values do not correlate with either the number of hydroxyl groups or the number of chelating sites. It is mainly decided by the stability of the Co(II)-phenol complex formed [59].

The hydroxyl radical scavenging assay is based on the generation of hydroxyl radical HOfrom $\mathrm{F}^{2+} / \mathrm{H}_{2} \mathrm{O}_{2}$ and used to evaluate the activity of aqueous methanol extracts. The scavenging abilities of bran control and bran treated with four carbohydrases on $\mathrm{HO}$ - radical inhibition are shown in figure 5. Alpha-amylase sample inhibition percentage (24.3\%) was significantly lower than control (31.6\%). However, samples treated with viscozyme, cellulase and amyloglucosidase had significantly higher $\mathrm{HO} \cdot$ inhibition power then control. The $\mathrm{HO} \cdot$ radicals scavenging of compounds have been attributed to the combined effects of reducing power, donation of hydrogen atoms and scavenging of active oxygen [83]. The antioxidant activity of phenolics is mainly due to their redox properties, which allow them to act as reducing agents, hydrogen donators, and singlet oxygen quenchers. Phenol compounds with multiple hydroxyl groups have also been shown to have better radical scavenging properties than compounds with mono-hydroxylated ring. Total phenolic content of alpha-amylase treated bran sample is 
higher than control, however its $\mathrm{HO} \cdot$ inhibition activity is lower and this may be explained by the number of phenolic hydroxyl groups.

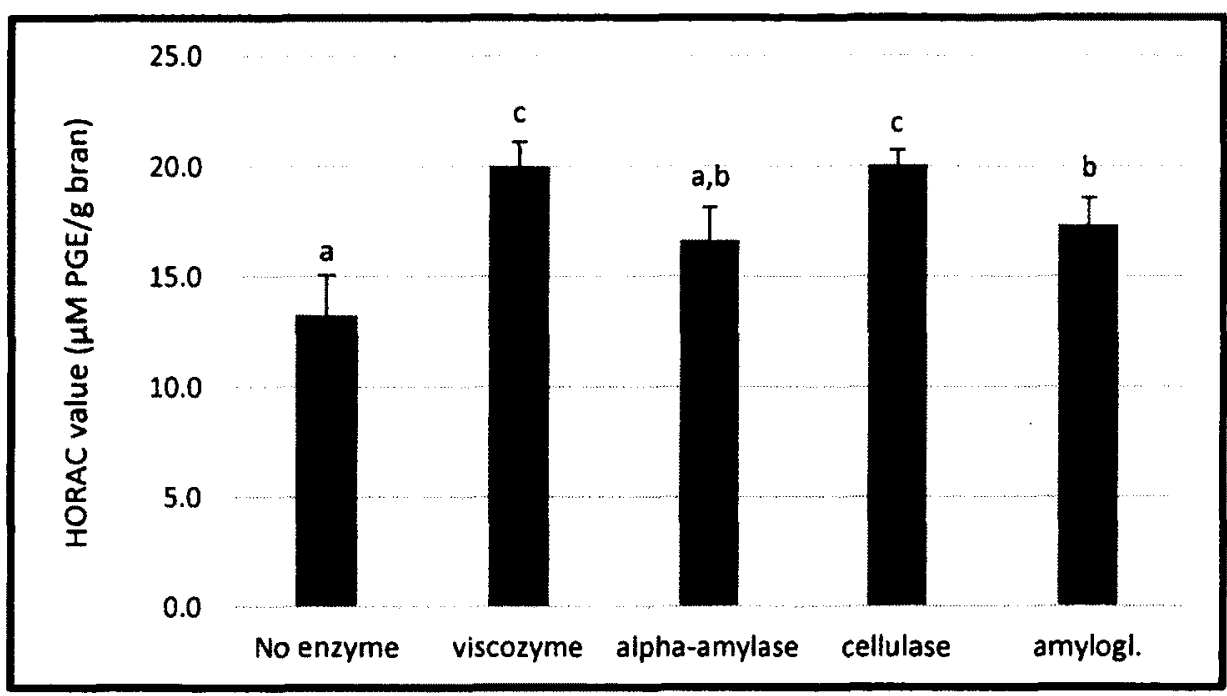

Figure 4: Hydroxyl radical scavenging activity of control and carbohydrases treated samples. Values are means of triplicates \pm standard deviation. SPL CTL: sample control, Amyloglu.: amyloglucosidase. Means with same letters are not significantly different according to an LSD test (alpha level $=0.05$ )

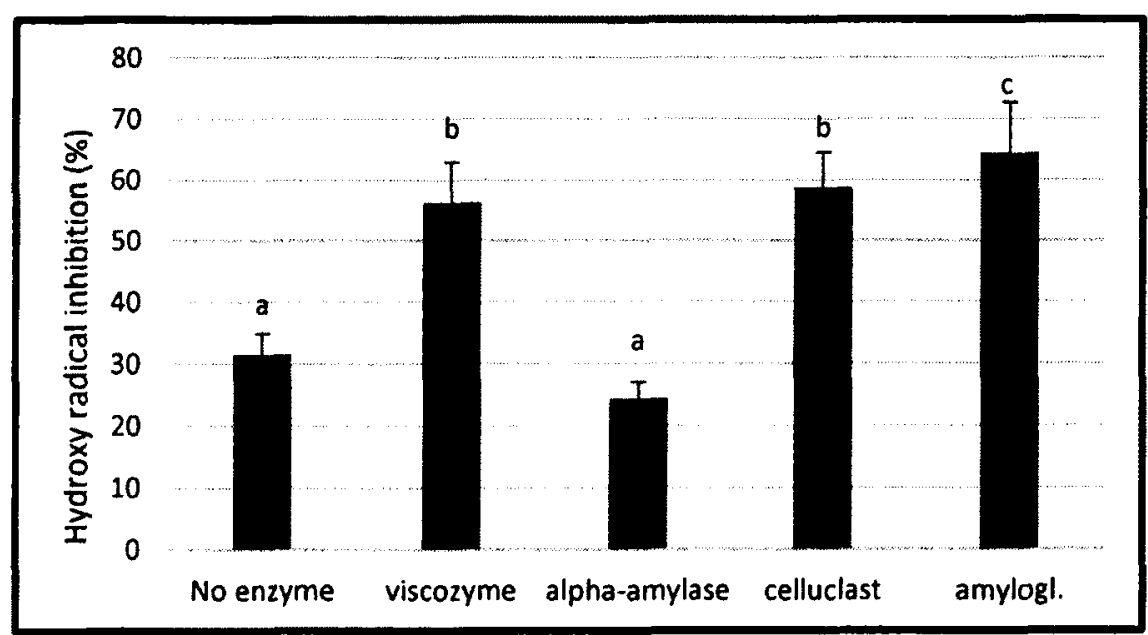

Figure 5: Hydroxyl radical scavenging activity of control and carbohydrases treated samples. Values are means of triplicates \pm standard deviation. Amylogl.: amyloglucosidase. Different letters indicate significant difference $(P<0.05)$ 


\section{Superoxide scavenging activity}

Superoxide anion is a reduced form of molecular oxygen created by receiving one electron, which is also an initial free radical formed from mitochondrial electron transport systems [84]. Superoxide radical is known to be a very harmful species to cellular components because it is a precursor of more reactive oxygen species. The superoxide radical is known to be produced in vivo and can result in the formation of $\mathrm{H}_{2} \mathrm{O}_{2}$ via dismutation reaction [85]. Superoxide anion radicals $\left(\mathrm{O}_{2} \bullet^{-}\right)$were generated by a pyrogallol autoxidation system. The $\mathrm{O}_{2} \bullet^{-}$radicals are scavenged by antioxidants and consequently, decrease the rate of pyrogallol autoxidation. The ability of water-methanol extracts to scavenge $\mathrm{O}_{2} \bullet-$ was carried out using this system and the results are reported in Figure 6 . The lower absorbance indicates higher inhibition of superoxide radical. Scavenging activity of cellulase pretreated methanol-water was the highest (19\%). Alpha-amylase and amyloglucosidase samples have comparable $\mathrm{O}_{2}$ scavenging activity, but this was significantly lower than the control sample. Finally viscozyme sample activity was similar to control. Some phenolic compound are known scavengers of $\mathrm{O}_{2} \bullet^{\bullet} ;$ however their presence in the extracts obtained from carbohydrase treated samples have not always been associated with increased activity [86]. Robak and Glyglewski [87] reported that flavonoids are effective antioxidants mainly because they scavenge superoxide anions. Without complete chemical analysis it may be difficult to exactly know chemicals that have the most influence on activity. 


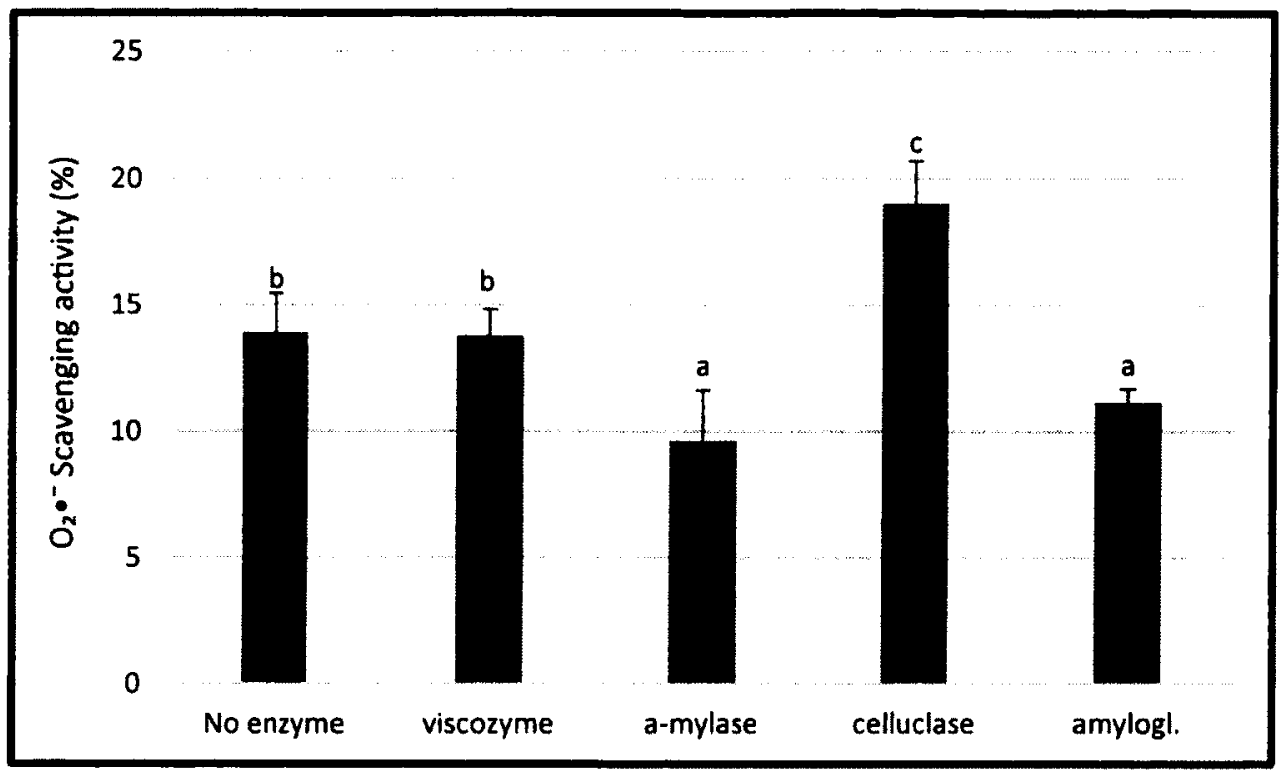

Figure 6: Superoxide anion radical scavenging activities of control and carbohydrases treated samples. Values are means of triplicates \pm SD. Amylogl.: amyloglucosidase. Bars with different letters are significantly different at $p<0.05$.

\section{Diphenyl-1-picrylhydrazyl (DPPH) radical scavenging activity}

The stable DPPH radical is widely used to evaluate the ability of food or food molecules to act as free radicals scavengers or hydrogen donors [61]. The absorbance of ethanolic or methanolic DPPH solution at $517 \mathrm{~nm}$ is gradually reduced while the free radicals are been scavenged [88]. The reduction in absorbance is due the transfer of a proton or electron from a donating substance (e.g. antioxidant) to the DPPH free radical [89]. This assay was used to evaluate the scavenging capacity of control and carbohydrates treated methanolic oat bran extracts (Figure 7). It was found that three of the carbohydrases significantly scavenged DPPH radicals when compared to control. Cellulase and amyloglucosidase showed the greatest increase in radical scavenging with the average DPPH inhibition increase of $22.5 \%$. Viscozyme showed a lower significant DPPH inhibition increase of $10 \%$. Meanwhile, percentage inhibition 
of sample treated with alpha-amylase was not significantly different when compared to inhibition of control sample.

Several studies have attempted to correlate the DPPH scavenging activity of molecules to total phenolic content and to individual phenolic acids. In that respect, Pereira et al. (2009) found that there was no direct correlation between DPPH inhibitory activity and total phenols, ferulic or caffeic acids content of Radix angelicae sinensis, although they reported a correlation with $1 / I_{50}$ values. Total phenolic contents of barley samples correlated with DPPH inhibitory capacity [90]. Verardo et al. [5] found a strong correlation $\left(r^{2}=0.93\right)$ of DPPH result of five oat cultivars to total free phenolic correlation. In this study the correction $\left(r^{2}=0.54\right)$ between DPPH and total free phenolic acids for the four carbohydrases treated samples is much weaker. One possible explanation is that the previous study quantified more phenolic acids including avenanthramides than the present investigation.

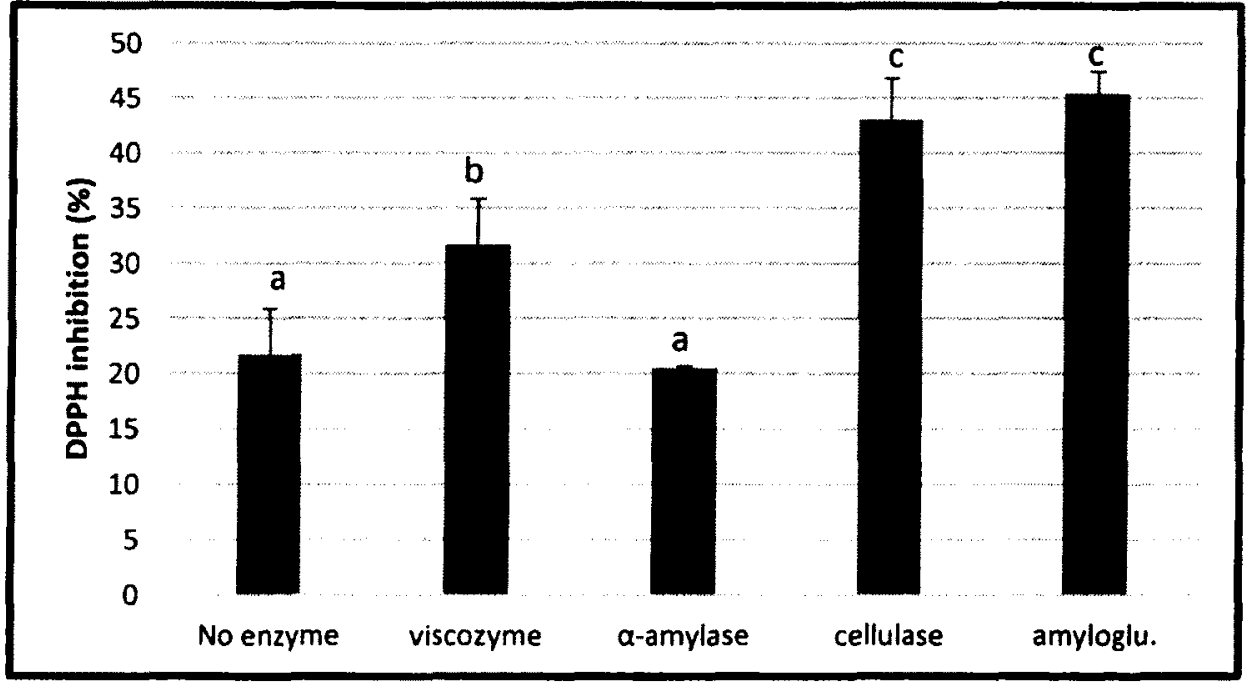

Figure 7: DPPH radical inhibition percentage values of control and carbohydrases treated samples. Values are mean \pm SD $(n=3)$.SPL CTL: sample control, Amyloglu.: amyloglucosidase. Means with same letters are not significantly different according to an LSD test (alpha level = 0.05). 


\section{Metal chelation}

The chelation of metal ions can decrease the amount of free iron available to participate in the Fenton reaction and ultimately decrease the formation of the $\mathrm{OH}$ radical [91]. The procedure was used to test the ferrous ion $\left(\mathrm{Fe}^{2+}\right)$ chelating efficiency of soluble compounds in aqueous methanol from oat bran. Ferrozine forms a complex with $\mathrm{Fe}^{2+}$ which is not completed in the presence of chelating agents in the plant extract, indicating their ability to chelate the iron when there is a decrease in the absorbance and the complex red color. In this assay, we found that at the exception of cellulase treated bran sample chelating activities, expressed as percentage inhibition of other carbohydrases treated samples, were significantly higher than the control (Fig. 8). The sample with the highest activity (16.6\%) was treated with amyloglucosidase. The presence of two adjacent hydroxyl groups in the polyphenol ring moieties were shown to increase their binding to transition metal ions [92] like iron and copper. Therefore, these types of phenols possess better chelating ability [92]. The lower binding properties of alpha-amylase treated sample may then be due to the lower concentration of phenols with two adjacent hydroxyl groups. 


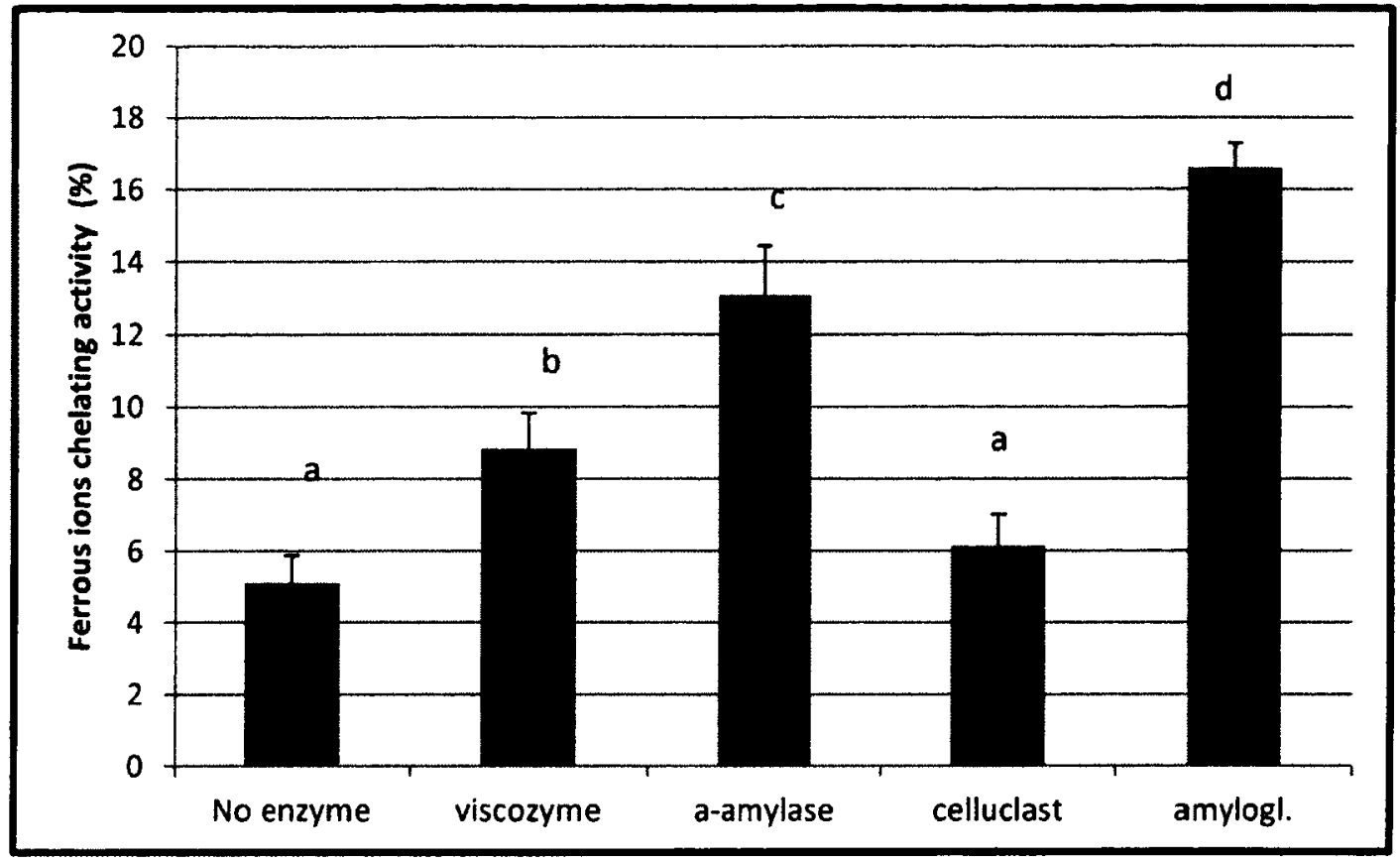

Figure 8: Ferrous ion-chelating properties of control and carbohydrases treated samples at 1.0 $\mathrm{mg} / \mathrm{ml}$ of extract. Each value is expressed as mean $\pm \mathrm{SD}(\mathrm{n}=3)$. Amylogl.: amyloglucosidase. Different letters indicate significant difference $(P<0.05)$

\section{Inhibition of linoleic acid auto-oxidation}

Lipids contain unsaturated fatty acid which undergoes peroxidation. The lipid peroxidation is known as the most damaging process to every living organism and can also causes deleterious effects in foods $[62,93]$. Peroxides had the potential to induce oxidation of ferrous iron to ferric iron which, can then reacts with ammonium thiocyanate to forming a colored complex that is measured by spectrophotometry. The lower the absorbance, the stronger is the antioxidant activity of extracts of molecules. As shown in figure 9 , control Linoleic acid had a typical increase in lipid hydroperoxides formation over time. The addition of the viscozyme treated sample did not decrease lipid hydroperoxide formation relative to the control linoleic acid (LA). Conversely, the alpha-amylase, cellulase, and amyloglucosidase treated samples showed a marked reduction in peroxidation relative to the control LA. The inhibition of 
peroxidation in these three enzyme treated samples was equivalent to that of alphatocopherol.

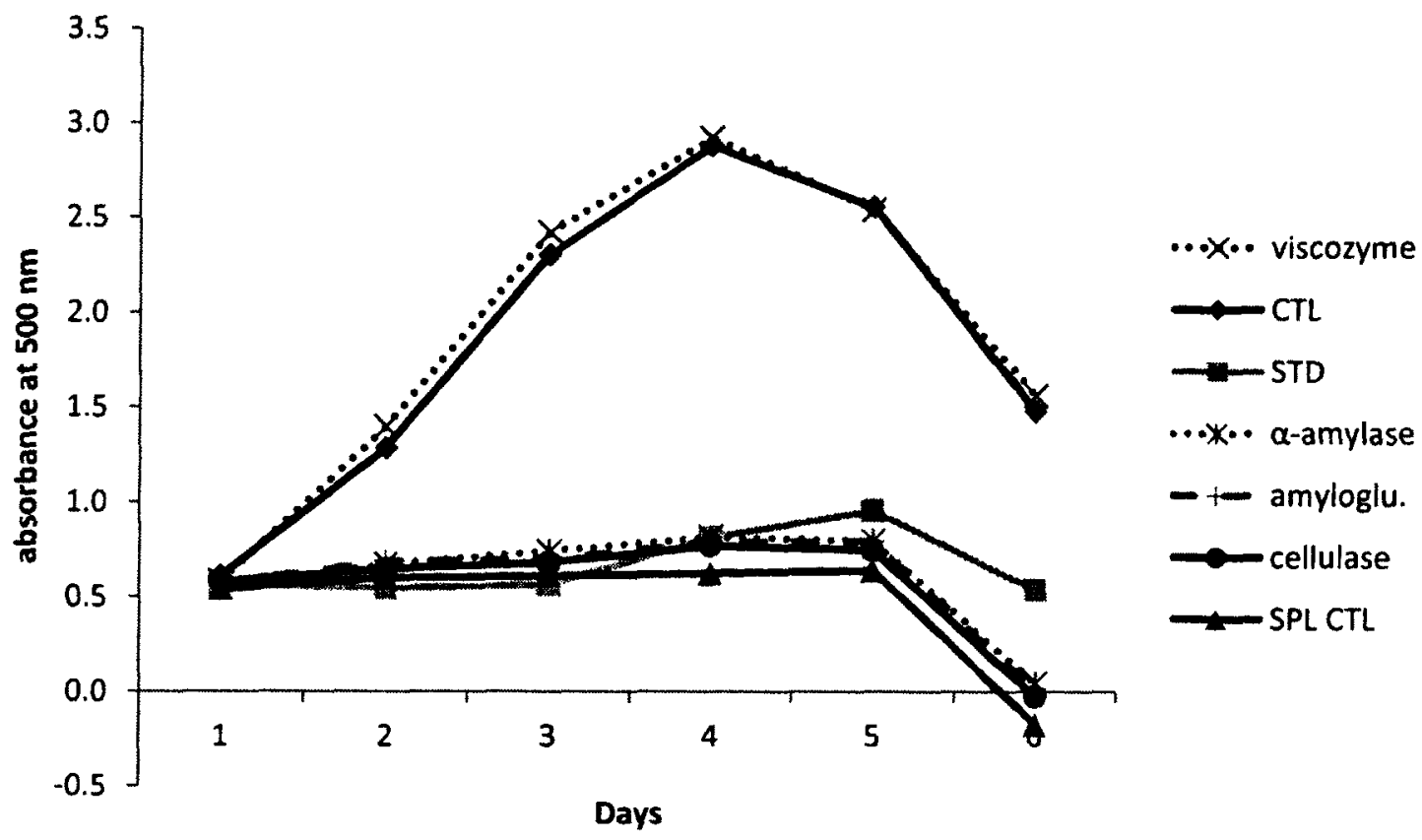

Figure 9: Inhibition of lipid hydroperoxides formation in the linoleic acid emulsion assay. CTL: linoleic acid only, STD: standard (alpha-tocopherol), SPL CTL: sample control, amyloglu.: amyloglucosidase. 


\section{Phenolic acid content}

Enzyme addition at concentrations described in the experimental section were used to obtain extracts rich in phenolic acids that were quantified by HPLC. We focussed on vanillic, caffeic, $p$-coumaric, ferulic and cinnamic acids because they are the main phenolic acids in oat $[94,95]$. Table 4 presents the content of these acids directly obtained from extracts or obtained after base hydrolysis of control and extracts obtained after treatment with four carbohydrases: viscozyme, alpha-amylase, cellulase and amyloglucosidase.

The free phenolic acids are from the methanol: water (50:50) extracts that were partitioned with ethyl acetate. The content of most phenolic acids (Table 4) in sample treated with carbohydrases is significantly higher compared to sample control. More specifically, vanillin and caffeic acids significantly increased in oat bran treated with viscozyme, alpha-amylase and cellulose, but not amyloglucosidase. Highest increase in vanillic and caffeic acid relative to the control was achieved by cellulose (3.7-fold) and viscozyme (4.4-fold), respectively. p-Coumaric acid significantly increased in oat bran digested with viscozyme (2.9-fold) and alpha-amylase (2.3-fold) compared to the control whereas it did not increase with cellulose or amyloglucosidase. Ferulic acid content significantly increased with all enzyme treatments and alpha-amylase showed the greatest increase (9.9-fold relative to the control). Only alphaamylase increased cinnamic acid content whereas viscozyme decrease its content relative to the untreated control. Cinnamic acid was not quantified in amyloglucosidase sample due to overlapping of its peak in HPLC chromatograms. The amount of each of the four phenolic acids identified here in sample control is much higher compared to value reported from five Italian and five Romanian oat cultivars [5] obtained with 4:1 aqueous mixtures of methanol, acetone 
and ethanol. This could be explained by the weaker polar strength of the extraction solvents relative to the 1:1 aqueous methanol used in the present study. Another difference is that our results are expressed per gram of bran while results from Verardo et al. are expressed per gram of whole seeds. It is well known that phenolic acids are more concentrated in oat bran [72, 96]. Emmons et al.[72] examined phenolic acids content in methanol extracts of different oat milling fractions and reported a vanillic acid content of up to $20 \mu \mathrm{g} / \mathrm{g}$ of fraction, which is higher than its value in the control and most tested enzyme-treated samples (except cellulase) from the present investigation. Literature values of caffeic, $p$-coumaric and ferulic acids Verardo et al. [5] are generally lower than those obtained for all samples in the present study. However there is one report of higher concentrations of caffeic $(14.3 \mu \mathrm{g} / \mathrm{g}), p$-coumaric $(23.8 \mu \mathrm{g} / \mathrm{g})$ and ferulic acids $(187.5 \mu \mathrm{g} / \mathrm{g})$ in whole oat grains [97].

The sum of free phenolic acid in the control sample was $121.7 \pm 4.3 \mu \mathrm{g} / \mathrm{g}$. This amount is slightly higher than the concentration of total free phenolic acids $(63.1 \pm 3.9$ to $115.1 \pm 0.3$ $\mu \mathrm{g} / \mathrm{g}$ ) reported in commercial oats and four Romanian oat cultivars [5]. A fifth cultivar however, contained more total free phenolic acids $(196.9 \pm 5.5 \mu \mathrm{g} / \mathrm{g}$ ) compared to sample control from this study. Amyloglucosidase treatment provided a lower total free phenols $(61.4 \pm 4.9 \mu \mathrm{g} / \mathrm{g})$ relative to control while the other three enzymes gave extracts with total free phenolic acid content ( 326.8 to $418.2 \mu \mathrm{g} / \mathrm{g}$ ) almost three times higher relative to control probably because of the release of some bound forms by the enzymes. In the literature, the fermentation of oats by filamentous fungi was successful used to increase the total and individual phenolic acids, specifically ferulic and caffeic acids [94]. 
The aqueous phases (after obtaining free phenols) were hydrolysed with sodium hydroxide for quantification of bound phenolic acids. Samples were analyzed under the same HPLC conditions. Base hydrolysis increased 6 to 11 -fold the amount of all acids except cinnamic acid whose bound-amount was lower in all samples relative to its amount in the free phenolic acid fractions (Table 4). The increase of phenolic acid after base hydrolysis is expected considering the fact that they are mainly linked to polysaccharides [55]. More specifically, caffeic acid increased following treatment with all enzymes except for amyloglucosidase. Alpha-amylase showed the highest increase (2.0-fold) in caffeic acid relative to the control. Ferulic acid content significantly increased following all enzymatic digestions relative to the control. The increase was particularly noticeable with alpha-amylase (3.5-fold) and cellulase (6.8-fold). For the other base hydrolyzed phenolic acids, increased content was shown for vanillic acid with alphaamylase, $p$-coumaric acid with cellulase, and cinnamic acid with alpha-amylase and cellulase (Table 4). 
Table 4 Phenolic acids in control and different enzyme-treated oat bran samples

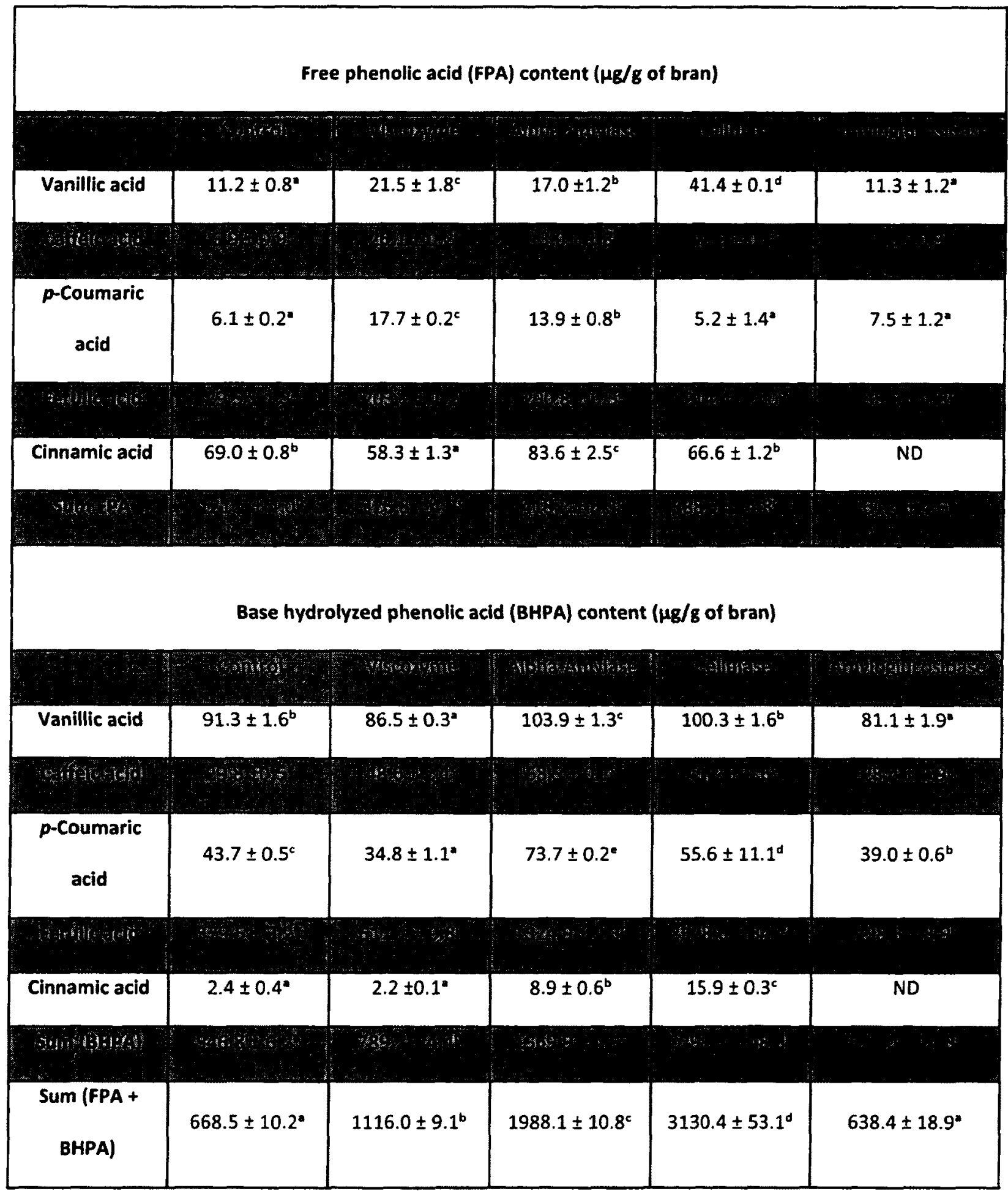

Data are the average of triplicate (means \pm SD) determined by HPLC analysis.

Within a row, means with the same letter are not significantly different according to an LSD test (alpha level $0.05)$

ND: Not determined due to overlapping 


\section{Antimicrobial activity}

Bacillus subtilis is a ubiquitous bacterium commonly recovered from water, soil, air, and decomposing plant residue. $B$. subtilis is not a human pathogen, nor is it toxigenic like some other members of the genus. It is present in the spore form that is tough to tolerate the extreme environmental conditions. Also, it is used as a model organism in laboratory studies as of the gram positive bacterium.

Escherichia coli, also known as $E$. coli is a gram positive rod-shaped bacterium that lives in human and animal intestines in large numbers and most of the strains are harmless. However, many strains of $E$. coli could cause serious food illness and therefore, there is a need to prevent or control the growth of these pathogenic strains [12].

For B. subtilis (Figure 10A), oat bran sample control (not digested with carbohydrases) surprisingly showed significantly lower bacterial growth (43\% less) that the negative control. Viscozyme and alpha-amylase treated oat bran samples significantly increased B. subtilis growth by $122 \%$ compared negative control. Growth of $B$. subtilis with cellulase and amyloglucosidase treated extracts was not significantly different from the negative control. For E. coli (Figure 10B), alpha-amylase treated sample, which demonstrated the least antioxidant activity in both DPPH and ORAC assays, and the sample control not treated with enzymes had no effect on the growth of $E$. coli while samples treated with viscozyme, cellulase, and amyloglucosidase equally reduced $E$. coli growth by approximately $37 \%$ when compared to controls.

The antimicrobial activity of phenolic compound is well known. Various phenolic extracts have been demonstrated to inhibit B. subtilis growth [98], while no effect has been obtained 
with others [99]. Alkyl gallates were found to be bactericidal against B. subtilis [100]. Probiotic activities of $B$. subtilis have been reported and ingestion of its cells is considered safe for humans under normal host conditions $[101,102]$. B. subtilis in used in the preparation of the soy food natto. Various beneficial attributes (e.g. superoxide dismutase activity, growth, survival, immune system) have been found in fish fed diets containing $B$. subtilis $[103,104]$. In fact, the release of the sugars after the pre-treatment with enzymes could work as a prebiotic and enhance the growth of Bacillus subtilis. In this study, there is no correlation between reducing sugar or releasing sugars and the growth of Bacillus subtilis. In the reducing sugar assay, sample treated with viscozyme got the higher amount of releasing sugar, but in the antimicrobial activity alpha-amylase got the higher amount of colony forming units (CFU).

Some studies indicated that phenolic acids have the ability to either interact with or cross cell membrane. For example, phenolic acids have been shown to cross $E$. coli cell membranes and exert their activity inside the cytoplasm $[105,106]$. Other work has shown that phenolics cause damage membranes leading to efflux of cellular component [107]. Gram- positive (e.g. B. subtilis) and gram-negative (e.g. E. coli) bacteria can have different sensitivity due to the differences in the cell membrane components and the structure of the membranes and cell walls [105].

In this study, the same extract was tested against some fungi species to investigate the effect of these extracts on the growth of the fungi. The disc diffusion assay against the Alternaria solani, Fusarium sambucinum and Pythium sulcatum did not show any significant results. The extracts did not inhibit the growth of any fungi species. 

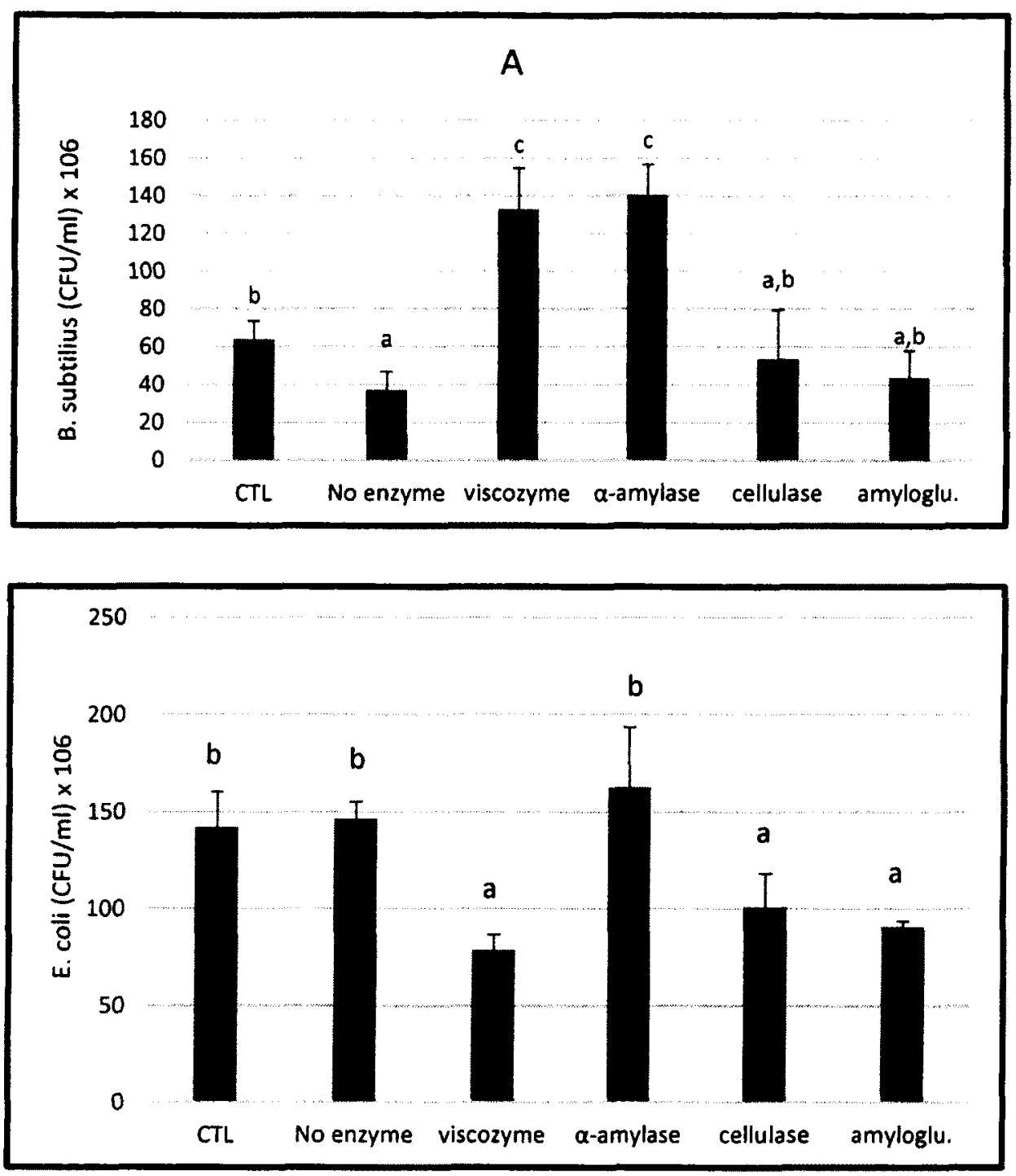

Figure 90: Effects of control and carbohydrases treated samples on the growth of microorganisms. (A): Bacillus subtilis. (B): Escherichia coli. CTL: control microorganisms (no treatment), SPL CTL: sample control, amyloglu: amyloglucosidase. Each value is expressed as mean $\pm S D(n=5)$. Means with same letters are not significantly different according to an LSD test (alpha level $=0.05$ ). 


\section{Chapter 5: Conclusion}

\section{Summary}

Oats have long been known for their nutritional benefits. Oats contain high levels of antioxidants, which is concentrated in the outer layers. This thesis has investigated the use of carbohydrases as a pre-treatment to achieve high concentration of phenolic acids in oat bran. The water-methanol extract of the enzymatic hydrolysis analyzed for quantified their phenolic acids content and determined their antioxidant and antimicrobial activities.

Lipid peroxidation is one of the most damaging forms of oxidation in the human body. It is initiated by the attack of hydroxyl radicals followed by the formation of alkoxyl radicals and the extension of the lipid chains. Superoxide anion could also act as an initiator of lipid peroxidation in erythrocyte membrane. Metal iron, presumably working as a catalyst, can stimulate lipid peroxidation by generating hydroxyl radicals via the Fenton reaction and accelerate lipid peroxidation by decomposing the lipid peroxidation products. Thus, antioxidants that can be used to protect lipid peroxidation are expected to have iron chelating and ROS scavenging activities.

The results from the extracts analysis demonstrated that pre-treatment of medium oat bran with four cell wall polysaccharide degrading enzymes significantly increase soluble phenolic content. Also, the individual and total phenolic acids content of oat bran samples increase upon treatment with carbohydrases, where the dominant phenolic acid was ferulic acid. The extract showed radical scavenging activities against peroxyl, hydroxyl and superoxide anion radicals, and ferrous ions chelating capacity. The results for the antimicrobial activity indicated that 
reducing the growth of $E$. coli, a potential food hazard, and enhancing the growth of $B$. subtilis, a potential pro-biotic strain, could contribute to food safety in the food manufacture field.

The alpha-amylase showed the least activity among the other carbohydrases in most of assays. The other enzymes as viscozyme, cellulase and amyloglucosidase showed more activity in most assays. The viscozyme treatment proved to be the most effective against the microbial growth.

\section{Future work}

Oat bran extract treated with carbohydrases can be useful in the development of functional foods with increase in lipid stability. Thus, more studies are needed to find optimum enzyme concentrations for preparation of oat bran phenolic extracts with increased antioxidant properties and to determine how they can be used as preservatives in processed foods.

Future work can also look at the bioavailability of the phenolic acids in intestinal cell lines and their cytoproctection the cell lines under condition of oxidative stress. 


\section{References}

1. Steinberg, J. Gold, J. Mitchell Fetch, and T. G. Fetch. 2005. "Evaluation of Avena spp. Accessions for Resistance to Oat Stem Rust." Plant Disease 89(5):521-525.

2. Sadiq Butt, Masood, Muhammad Tahir-Nadeem, Muhammad Kashif Iqbal Khan, Rabia Shabir, and Mehmood S Butt. 2008. "Oat: unique among the cereals." European journal of nutrition 47(2):68-79.

3. Peterson, David M. 2001. "Oat Antioxidants." Journal of Cereal Science 33(2):115129.

4. Peterson, David M. 2004. "Oat - a multifunctional grain " $7^{\text {th }}$ International Oat Conference. Report 15.

5. Verardo, Vito, Cristian Serea, Rodica Segal, and Maria Fiorenza Caboni. 2011. "Free and bound minor polar compounds in oats: Different extraction methods and analytical determinations." Journal of Cereal Science 54(2):211-217.

6. Simpson, Benjamin K. 2006. Food Biochemistry and Food Processing ( $\left.{ }^{\text {nd }} E D\right)$. Ames, lowa, Black well Publishing.

7. Andersson, Kristina $E$, and Per Hellstrand. 2012. "Dietary oats and modulation of atherogenic pathways." Molecular nutrition \& food research 56(7):1003-13.

8. Alrahmany, Roaaya, and Apollinaire Tsopmo. 2011. "Role of carbohydrases on the release of reducing sugar, total phenolics and on antioxidant properties of oat bran." Food Chemistry 132 (1): 413-418.

9. Neil, D, Neil Granger, and Joey Granger. n.d. Reactive Oxygen Species and the Cardiovascular System. Pp 3.(2012).

10. Gülçin, Ilhami, Münir Oktay, O Irfan Küfrevioğlu, and Ali Aslan. 2002.

"Determination of antioxidant activity of lichen Cetraria islandica (L) Ach." Journal of ethnopharmacology 79(3):325-9.

11. Gülçın, Illhami, Münir Oktay, Ekrem Kıreçcı, and Öirfan Küfrevıoğlu. 2003.

"Screening of antioxidant and antimicrobial activities of anise (Pimpinella anisum

L.) seed extracts." Food Chemistry 83(3):371-382.

12. Wu, Defeng and Cederbaum, Arthur. (2003) "Alcohol, oxidative stress, and free radical damage". Alcohol research and health. 27(4): 277-284.

13. Halliwell, Barry (1991) Reactive oxygen species in living system: source, biochemistry, and role in human disease. The American Journal of medicine $91(3 \mathrm{C}): 14 \mathrm{~s}-22 \mathrm{~s}$. 
14. Zhao, Lingjie, Lingjie Zhao, Singlet Oxygen and Free Radical. 2001. "Singlet Oxygen." 1-10.

15. Kumar, Shiv. 2011. "Free Radicals and Antioxidants : Human and Food System." 2(1):129-135.

16. Gill, Sarvajeet Singh, and Narendra Tuteja. 2010. "Reactive oxygen species and antioxidant machinery in abiotic stress tolerance in crop plants." Plant physiology and biochemistry : 48(12):909-930.

17. http://www.hindawi.com/journals/nrp/2011/260482/fig1. [01-09-2013, 11:00 pm].

18. Sivanandham, Velavan. 2011. "FREE RADICALS IN HEALTH AND DISEASES -." 1077:1062-1077.

19. Brouwers, J F, and B M Gadella. n.d.(2006). "Physiology of peroxidation processes in mammalian sperm, Chapter 1: Oxidative stress and fertility-aspects of molecular oxidation and their effects on the mammalian reproductive output". Pp:4-18.

20. Rahman, Khalid. 2007. "Studies on free radicals, antioxidants, and co-factors." Clinical interventions in aging 2(2):219-36.

21. Kevin, Leo G, Enis Novalija, and David F Stowe. 2005. "Reactive oxygen species as mediators of cardiac injury and protection: the relevance to anesthesia practice." Anesthesia and analgesia 101(5):1275-87.

22. Pala, Funda Sibel. 2007. "Free radicals : Our enemies or friends ? Funda Sibel Pala and $K$, ymet." (1):63-68.

23. Niedernhofer, Laura J, J Scott Daniels, Carol a Rouzer, Rachel E Greene, and Lawrence J Marnett. 2003. "Malondialdehyde, a product of lipid peroxidation, is mutagenic in human cells." The Journal of biological chemistry 278(33):31426-33.

24. Halliwell, Barry. 1993. "Lipid peroxidation : and significanc \& 3 its mechanism ,"

25. Wiseman, Helen, and Barry Halliwell. 1996. "inflammatory disease and progression to cancer." 29(2):17-29.

26. Dizaroglu, M. Jaruga, P. Birincioglu, $M$ and Rodriguez, H. 2002. "Serial Review : Oxidative DNA Damage and Repair." 32(11):1102-1115.

27. http://www.sciencedirect.com/science/article/pii/S0304383512000468 (12-192012, 2:04 PM)

28. De Bont, R. 2004. "Endogenous DNA damage in humans: a review of quantitative data." Mutagenesis 19(3):169-185. 
29. Berlett, B S, and E R Stadtman. 1997. "Protein oxidation in aging, disease, and oxidative stress." The Journal of biological chemistry 272(33):20313-6.

30. Dalle-Donne, Isabella, Ranieri Rossi, Daniela Giustarini, Aldo Milzani, and Roberto Colombo. 2003. "Protein carbonyl groups as biomarkers of oxidative stress." Clinica Chimica Acta 329(1-2):23-38.

31. Wu, D. 2003. "Free Radical damage" Alcohol. 2: 277-284.

32. Mandal, Sulekha, Satish Yadav, Sunita Yadav, and Rajesh Kumar Nema. 2009. "Antioxidants : A Review." 1(1):102-104.

33. Halliwell, Barry. 2001. "Free Radicals and other reactive species in Disease." 1-7.

34. Fang, Yun-Zhong, Sheng Yang, and Guoyao Wu. 2002. "Free radicals, antioxidants, and nutrition." Nutrition (Burbank, Los Angeles County, Calif.) 18(10):872-9.

35. Percival, M. 1996. "Antioxidants". Clinical Nutrition Insight.

36. Li, Xican. 2012. "Improved pyrogallol autoxidation method: a reliable and cheap superoxide-scavenging assay suitable for all antioxidants." Journal of agricultural and food chemistry 60(25):6418-24.

37. Chang, Christine C C et al. 2009. "Arabidopsis chloroplastic glutathione peroxidases play a role in cross talk between photooxidative stress and immune responses." Plant physiology 150(2):670-83.

38. Brouwers, J F, and B M Gadella. n.d. 2006 "Oxidative stress and fertility-aspects of molecular oxidation and their effects on the mammalian reproductive output."

39. Pakash, S. Sunitha, J. Hans, M. 2010. "Role of Co enzyme Q10 as an antioxidant and bionergizer in periodontal diseases". Indian Journal Pharmacology. 42(6): 334337.

40. Hurtado-fernández, Elena, María Gómez-romero, Alegría Carrasco-pancorbo, and Alberto Fernández-gutiérrez. 2010. "Journal of Pharmaceutical and Biomedical Analysis Application and potential of capillary electroseparation methods to determine antioxidant phenolic compounds from plant food material." 53:11301160.

41. Vermerris, W. Nicholson, R. 2009 "Phenolic compound biochemistry" (1 ${ }^{\text {st }}$ ed). Spring science.

42. Gani, Adil, Wani Sm, and Masoodi Fa. 2012. "Whole-Grain Cereal Bioactive Compounds and Their Health Benefits: A Review." Journal of Food Processing \& Technology 03(03). 
43. Dimberg, Lena H, Charlott Gissén, and Janicka Nilsson. 2005. "Phenolic compounds in oat grains (Avena sativa L.) grown in conventional and organic systems." Ambio 34(4-5):331-7.

43,a. http://www.dazzledish.com/blog/nutrition/an-oat-by-any-other-name-is-still-anoat-unless-it-is-instant/. [12-20-2012 11:17 AM].

44. Lasztity, R. 1998. "Oat grain- a wonderful reservoir of natural nutrients and biological active substances". Food Reviews International.14(1): 99-119.

45. Matz, S. (1991). "Chemistry and food technology of cereals as food and feed". $(2$ nd ed).

46. Sadiq Butt, Masood, Muhammad Tahir-Nadeem, Muhammad Kashif Iqbal Khan, Rabia Shabir, and Mehmood S Butt. 2008. "Oat: unique among the cereals." European journal of nutrition 47(2):68-79.

47. Dykes, L. and Rooney, L. 2007." Phenolic compounds in cereal grains and their health benefits" Cereal Food World. 52(3): 105-111.

48. Thompson, Lilian U, Beatrice a Boucher, Zhen Liu, Michelle Cotterchio, and Nancy Kreiger. 2006. "Phytoestrogen content of foods consumed in Canada, including isoflavones, lignans, and coumestan." Nutrition and cancer 54(2):184-201.

49. Garcõâa-estepa, Rosa M, and Eduardo Guerra-herna. 1999. "Phytic acid content in milled cereal products and breads." 32:217-221.

50. Katz, David L, and Yale Prevention. 2001. "A Scientific Review of the Health Benefits of Oats." 1-11.

51. Walker, J. 1975. "The Biology of Plant Phenolics".

52. Naczk, Marian, and Fereidoon Shahidi. 2004. "Extraction and analysis of phenolics in food." Journal of Chromatography A 1054(1-2):95-111.

53. Robbins, Rebecca J. 2003. "Phenolic acids in foods: an overview of analytical methodology." Journal of agricultural and food chemistry 51(10):2866-87.

54. Stalikas, Constantine D. 2007. "Review Extraction, separation, and detection methods for phenolic acids and flavonoids." 3268-3295.

54,a. Ann and Patrick Fullick .2001. "Chemistry of AQA". (1 ${ }^{\text {st }}$ ED) pp:130-133.

$54, b$. Joyce Boye (2012)." Green technology in food production and processing". (1 ${ }^{\text {st }}$ ED).

54,c. http://www.ncbe.reading.ac.uk/ncbe/materials/enzymes/viscozyme.html [01-07$201310: 30 \mathrm{AM}]$ 
55. Madhujith, Terrence, and Fereidoon Shahidi. 2007. "Antioxidative and antiproliferative properties of selected barley (Hordeum vulgarae L.) cultivars and their potential for inhibition of low-density lipoprotein (LDL) cholesterol oxidation." Journal of agricultural and food chemistry 55(13):5018-24.

56. Singleton, V. (1965). "Colorimetry of total phenolics with phosphomolybdic phosphotungstic reagent". American Journal of Enology and Viticulture. 16:144158.

57. Li, Wende, Farah S Hosseinian, Apollinaire Tsopmo, James K Friel, and Trust Beta. 2009. "Evaluation of antioxidant capacity and aroma quality of breast milk." Nutrition (Burbank, Los Angeles County, Calif.) 25(1):105-14.

58. Cao, G. H., \& Prior, R. L. (1999). Measurement of oxygen radical absorbance capacity in biological samples: Oxidants and antioxidants. Methods in Enzymology, 299,50-62.

59. Huang, D., Ou, B., Hampsch-Woodill, M., Flanagan, J. A., \& Prior, R. L. (2002). Highthroughput assay of oxygen radical absorbance capacity (ORAC) using a multichannel liquid handling system coupled with a microplate fluorescence reader in 96-well format. Journal of Agricultural and Food Chemistry, 50(16), $4437-4444$.

60. Ciz, M., Cizova, H., Denev, P., Kratchanova, M., Slavov, A., \& Lojek, A. (2010). Different methods for control and comparison of the antioxidant properties of vegetables. Food Control, 21(4), 518-523.

61. Pownall, T. L., Udenigwe, C. C., \& Aluko, R. (2010). Amino acid composition and antioxidant properties of pea seed (Pisum sativum L.) enzymatic protein hydrolysate fractions. Journal of Agricultural and Food Chemistry, 58(8), 47124718.

62. Li, Y. H., Jiang, B., Zhang, T., Mu, W. M., \& Liu, J. (2008). Antioxidant and free radical-scavenging activities of chickpea protein hydrolysate (CPH). Food Chemistry, 106(2), 444-450.

63. Udenigwe, C. C., Lu, Y. -., Han, C. -., Hou, W. -., \& Aluko, R. E. (2009). Flaxseed protein-derived peptide fractions: antioxidant properties and inhibition of lipopolysaccharide-induced nitric oxide production in murine macrophages. Food Chemistry, 116, 277-284.

64. Xie, Z., Huang, J., Xu, X., \& Jin, Z. (2008). Antioxidant activity of peptides isolated from alfalfa leaf protein hydrolysate. Food Chemistry, 111(2), 370-376.

65. Osawa, T., \& Namiki, M. (1985). Natural antioxidant isolated from eucalyptus leaf waxes. Journal of Agricutural and Food Chemistry, 33(5), 777-780. 
66. Kim, K., Tsao, R., Yang, R., \& Cui, S. (2006). Phenolic acid profiles and antioxidant activities of wheat bran extracts and the effect of hydrolysis conditions. Food Chemistry, 95(3), 466-473.

67. Zheng, Hu-zhe, In-Wook Hwang, and Shin-Kyo Chung. 2009. "Enhancing polyphenol extraction from unripe apples by carbohydrate-hydrolyzing enzymes." Journal of Zhejiang University. Science. B 10(12):912-9.

68. Kapasakalidis, P. G., Rastall, R. A., \& Gordon, M. H. (2009). Effect of a cellulase treatment on extraction of antioxidant phenols from black currant (Ribes nigrum L.) pomace. Journal of Agricultural and Food Chemistry, 57(10), 4342-4351.

69. Guan, X., \& Yao, H. (2008). Optimization of viscozyme L-assisted extraction of oat bran protein using response surface methodology. Food Chemistry, 106(1), 345351.

70. Tang, S., Hettiarachchy, N. S., Eswaranandam, S., \& Crandall, P. (2003). Protein extraction from heat-stabilised defatted rice bran: II. The role of amylase, celluclast, and viscozyme. Journal of Food Science, 68(2), 471-475.

71. Kováčová, M., \& Malinová, E. (2007). Ferulic and coumaric acids, total phenolic compounds and their correlation in selected oat genotypes. , 25, 325-332.

72. Emmons, C. L., \& Peterson, D. M. (1999). Antioxidant activity and phenolic contents of oat groats and hulls. Cereal Chemistry, 76(6), 902-906.

73. Tian, B., Xie, B., Shi, J., Wu, J., Cai, Y., Xu, T., Xue, S., \& Deng, Q. (2010). Physicochemical changes of oat seeds during germination. Food Chemistry, 119(3), 1195-1200.

74. Davalos, A., Gomez-Cordoves, C., \& Bartolome, B. (2004). Extending applicability of the oxygen radical absorbance capacity (ORAC-fluorescence) assay. Journal of Agricultural and Food Chemistry, 52, 48-54.

75. Prior, R., Wu, X., \& Kschaich, K. (2005). Standardized methods for the determination of antioxidant capacity and phenolics in foods and dietary supplements. . Journal of Agricultural and Food Chemistry, 53(4290), 4302.

76. Je, J.-., Park, P.-., Kim, E.-., Park, J.-., Yoon, H.-., Kim, K.-., et al. (2009). Antioxidant activity of enzymatic extracts from the brown seaweed Undaria pinnatifida by electron spin resonance spectroscopy. LWT-Food Science and Technology, 42(4), 874-878.

77. Duenas, M., Hernandez, T., \& Estrella, I. (2007). Changes in the content of bioactive polyphenolic compounds of lentils by the action of exogenous enzymes. Effect on their antioxidant activity. Food Chemistry, 101(1), 90-97.

78. Handelman, G. J., Cao, G., Walter, M. F., Nightingale, Z. D., Paul, G. L., Prior, R. L., \& . Blumberg, J. B. (1999). Antioxidant capacity of oat (Avena sativa L.) extracts. 1. 
Inhibition of low-density lipoprotein oxidation and oxygen radical absorbance capacity. Journal of Agricultural and Food Chemistry, 47, 4888-4893.

79. Liyana-Pathirana, C. M., \& Shahidi, F. (2006). Importance of insoluble-bound phenolics to antioxidant properties of wheat. Journal of Agricultural and Food Chemistry, 54, 1256-1264.

80. Lee, J., Koo, N., \& D.B. Min, D. B. (2004). Reactive oxygen species, aging, and antioxidative nutraceuticals. Comprehensive Reviews in Food Science and Food Safety, 3, 21-33.

81. Dubost,N.J.Ou,B.Beelman,R.B. (2007). Quantification of polyphenols and ergothioneine in cultivated mushrooms and correlation to total antioxidant capacity. Food Chemistry, 105(2), 727-735.

82. Ou, B., Hampsch-Woodill, M., Flanagan, J., Deemer, E., Prior, R., \& Huang, D. (2002). Novel fluorometric assay for hydroxyl radical prevention capacity using fluorescein as the probe. Journal of Agricultural and Food Chemistry, 50(10), 27722777.

83. Rice-Evans, C. A., Miller, N. J., Bolwell, P. G., Bramley, P. M., \& Pridham, J. B. (1995). The relative antioxidant activities of plant-derived polyphenolic flavonoids. Free Radical Research, 22, 375-384.

84. Siddhuraju, P., \& Becker, K. (2007). The antioxidant and free radical scavenging activities of processed cowpea (Vigna unguiculata (L.) Walp.) seed extracts. Food Chemistry, 101(1), 10-19.

85. Li, X. M., Li, X. L., \& Zhou, A. G. (2007). Evaluation of antioxidant activity of the polysaccharides extracted from Lycium barbarum fruits in vitro. European Polymer Journal, 43(2), 488-497.

86. Sun, T., Powers, J. R., \& Tang, J. (2007). Effect of enzymatic macerate treatment on rutin content, antioxidant activity, yield, and physical properties of asparagus juice. Journal of Food Science, 72(4), S267-S271.

87. Zhishen, J., Mengcheng, T., \& Jianming, W. (1999). The determination of flavonoid content in mulberry and their scavenging effects on superoxide radicals. Food Chemistry, 64, 555-559.

88. Yamashoji, S., \& Kajimoto, G. (1980). Antioxidant Effect of Gly-Gly-His on Cu(ii)Catalyzed Autoxidation and Photosensitized Oxidation of Lipids. Agricultural and Biological Chemistry, 44(11), 2735-2736.

89. Wang, J. S., Zhao, M. M., Zhao, Q. Z., \& Jiang, Y. M. (2007). Antioxidant properties of papain hydrolysates of wheat gluten in different oxidation systems. Food Chemistry, 101(4), 1658-1663. 
90. Gamel, T. H., \& Abdel-Aal, E. M. (2012). Phenolic acids and antioxidant properties of barley wholegrain and pearling fractions. Agricultural and Food Science, 21(2), 118-131.

91. Halliwell, B., \& Gutteridge, J. M. C. (1990). Role of free radicals and catalytic metal ions in human disease: an overview. Methods in Enzymology, 186, 1-85.

92. Miguel, M. G., \& Nunes, S. (2010). Phenols and antioxidant activity of hydroalcoholic extracts of propolis from Algarve, South of Portugal. Food and Chemical Toxicology, 48, 3418-3423.

93. Gill, S. S., \& Tuteja, N. (2010). Reactive oxygen species and antioxidant machinery in abiotic stress tolerance in crop plants. Plant Physiology and Biochemistry, 48(12), 909-930.

94. Cai, S., Wang, O., Wu, W., Zhu, S., Zhou, F., Ji, B., Gao, F., Zhang, D., Liu, J., \& Cheng, Q. (2012). Comparative Study of the Effects of Solid-State Fermentation with Three Filamentous Fungi on the Total Phenolics Content (TPC), Flavonoids, and Antioxidant Activities of Subfractions from Oats (Avena sativa L.). Journal of Agricultural and Food Chemistry, 60(1), 507-513.

95. Durkee, A., \& Thivierge, P. (1977). Ferulic acid and other phenolics in oat seeds (Avena sativa L var hinoat). Journal of Food Science, 42(2), 551-552.

96. Liu, L., Zubik, L., Collins, F., Marko, M., \& Meydani, M. (2004). The antiatherogenic potential of oat phenolic compounds. Atherosclerosis, 175(1), 39-49.

97. Xu, J. G., Tian, C. R., Hu, Q. P., Luo, J. Y., Wang, X. D., \& Tian, X. D. (2009). Dynamic Changes in Phenolic Compounds and Antioxidant Activity in Oats (Avena nuda L.) during Steeping and Germination. Journal of Agricultural and Food Chemistry, 57(21), 10392-10398.

98. Ayaz, F., Hayirlioglu-Ayaz, S., Alpay-Karaoglu, S., Gruz, J., Valentova, K., Ulrichova, J., \& Strnad, M. (2008). Phenolic acid contents of kale (Brassica oleraceae L. var. acephala DC.) extracts and their antioxidant and antibacterial activities. Food Chemistry, 107(1), 19-25.

99. Baydar, N., Ozkan, G., \& Sagdic, O. (2004). Total phenolic contents and antibacterial activities of grape (Vitis vinifera L.) extracts. Food Control, 15(5), 335339.

100. Kubo, I., Fujita, K., Nihei, K., \& Nihei, A. (2004). Antibacterial activity of akyl gallates against Bacillus subtilis. Journal of Agricultural and Food Chemistry, 52(5), 1072-1076. 
101. Baneyx, F., Ayling, A., Palumno, T., Thomas, D., \& Georgiou, G. (1991).

Optimization of growth-conditions for the production of proteolytically-sensitive proteins in the periplasmic space of Escherichia-coli. Applied Microbiology and Biotechnology, 36(1), 14-20.

102. DeBoer, A., \& Diderichsen, B. (1991). On the safety of Bacillus subtilis and BAmyloliquefaciens - a Review. Applied Microbiology and Biotechnology, 36(1), 1-4.

103. Newaj-Fyzul, A., Adesiyun, A. A., Mutani, A., Ramsubhag, A., Brunt, J., \& Austin, B. (2007). Bacillus subtilis $A B 1$ controls Aeromonas infection in rainbow trout (Oncorhynchus mykiss, Walbaum). Journal of applied microbiology, 103(5), 1699. 1706.

104. Salinas, I., Cuesta, A., Esteban, M., \& Meseguer, J. (2005). Dietary administration of Lactobacillus delbrueckii and Bacillus subtilis, single or combined, on gilthead seabream cellular innate immune responses. Fish \& shellfish immunology, 19(1), 67-77.

105. Cueva, C., Victoria Moreno-Arribas, M., Martin-Alvarez, P. J., Bills, G., Francisca Vicente, M., Basilio, A., Lopez Rivas, C., Requena, T., Rodriguez, J. M., \& Bartolome, B. (2010). Antimicrobial activity of phenolic acids against commensal, probiotic and pathogenic bacteria. Research in microbiology, 161(5), 372-382.

106. kigai, H., Nakae, T., Hara, Y., \& Sshmamura, T. (1993). Bactericidal ctechins dmage the Ipid blayer. Biochimica et biophysica acta, 1147(1), 132-136.

107. Campos, F. M., Couto, J. A., Figueiredo, A. R., Toth, I. V., Rangel, A. O. S. S., \& Hogg, T. A. (2009). Cell membrane damage induced by phenolic acids on wine lactic acid bacteria. International journal of food microbiology, 135(2), 144-151. 